\title{
POLÍTICAS INDÍGENAS EN CHILE (SIGLOS XIX Y XX) DE LA ASIMILACIÓN AL PLURALISMO (EL CASO MAPUCHE)*
}

\author{
POR \\ GUILLAUME BOCCARA \\ CNRS-EHESS, París (Francia) \\ INGRID SEGUEL-BOCCARA \\ Post-doct. Lavoisier, París (Francia)
}

Antes de que la ley indígena de 1993 reconociera la existencia del pluralismo cultural en el territorio nacional y sentara las bases de la participación de las «etnias chilenas» en las políticas aplicadas por el Estado, los pueblos autóctonos eran meros objetos del derecho. En efecto, la política indígena implementada por el Estado chileno desde su indenpendencia fue fundamentalmente caracterizada por la voluntad de asimilar a los autóctonos. En este artículo analizamos la naturaleza de las relaciones que la Nación chilena (imaginada como homogénea y europea) y el Estado (centralista y en busca de unidad territorial) establecieron con los mapuches, uno de los pueblos indígenas más numerosos de América Latina.

\section{INTRODUCCIÓN $^{1}$}

Antes de que la ley 19.253 de 1993 reconociera la existencia del pluralismo cultural en el territorio nacional y sentara las bases de la participación indígena trabajo.

* Agradecemos a Jaime Ibacache y Eliseo Cañulef la lectura crítica que hicieron de nuestro

1 A pesar de que la ley indígena reconozca la existencia de ocho etnias en el territorio nacional chileno (Mapuche, Aymara, Rapa Nui, Atacameña, Quechua, Colla, Kawashkar, Yámana), en este artículo solamente trataremos de las políticas indígenas en relación a los Mapuches del centro-sur de Chile. Con un total de 928060 personas de 14 años y más que reconocen pertenecer a la cultura mapuche (Censo Nacional de Población 1992) este pueblo representa más del 95\% de la población indígena de este país. Para más antecedentes sobre los otros pueblos indígenas véase: José AYLWIN,

R. I., $1999, \mathrm{n}^{\circ} 217$ 
en las políticas aplicadas por el Estado a las «etnias descendientes de las agrupaciones humanas precolombinas» ${ }^{2}$, los pueblos autóctonos chilenos eran meros objetos del derecho. El papel pasivo que se les atribuía se remite fundamentalmente a la relación que el Estado chileno estableció desde su inicio con los pueblos indígenas: una relación «marcada por el interés de poner la unidad territorial y la hegemonía racial por sobre la diversidad cultural existente» ${ }^{3}$.

Ahora bien, si la política indígena implementada por el Estado chileno desde la independencia ha sido fundamentalmente caracterizada por la voluntad de asimilar a los autóctonos, es posible distinguir, en función del contexto sociohistórico, de los medios empleados y de las formas jurídicas de desposeimiento, varios momentos en esa larga historia de negación de la especificidad indígena y de despojo de los territorios habitados por esos pueblos.

Durante el primer periodo (1818-1850), si bien se declara la igualdad jurídica de los indígenas, veremos que los medios empleados (evangelización, parlamentos y colonización poblacional) para enfrentar el problema indígena no se diferencian mucho de los usados por las autoridades hispanocriollas durante el siglo XVIII.

A partir de 1850, frente a la penetración incontrolada de colonos y dado el nuevo interés que despertaron las tierras aún libres al sur del Bío-Bío, el Estado empleó las armas de la conquista territorial y de la apropiación por el fisco de las tierras indígenas. El anti-indigenismo doctrinal se impuso y los descendientes de «los héroes de la guerra de Arauco», ensalzados durante la independencia, pasaron a ser considerados como un obstáculo a la modernización del país.

Una vez concluida la mal llamada «pacificación de la Araucanía» y asegurada la derrota militar de los Mapuches $(1883)^{4}$, el Estado se aplicó a la radicación

\footnotetext{
«Nueva legislación indígena: avance hacia una nueva relación entre el estado y los pueblos indígenas de Chile», en Anuario Indigenista, vol. XXXII. México, Instituto Indigenista Interamericano, 1993, pp. 9-21; Anne Chapman, Los Selk'nam. La vida de los Onas. Buenos Aires, Emecé Editores, 1998 (1era edición en inglés 1982); Hans GundERMANN K., «Comunidad Aymara, identidades colectivas y estados nacionales en los albores del siglo XX», en Sergio GonZaLEZ (Coord.), A 90 años de los sucesos de la Escuela Santa María de Iquique. Santiago, Lom Ediciones, 1998, pp. 153-181 y «Etnicidad, identidad étnica y ciudadanía en los países andinos y el norte de Chile», en Estudios Atacameños, $\mathrm{n}^{\circ}$ 13. San Pedro de Atacama, Universidad Católica del Norte, 1998, pp. 926; Jorge HidAlgo, et al., Culturas de Chile. Etnografía. Sociedades indígenas contemporáneas y su ideología. Santiago, Editorial Andrés Bello, 1996. artículo $1^{\circ}$.

2 Ley indígena 19.253. Santiago, Comisión Especial de Pueblos Indígenas, 1993, Párrafo $1^{\circ}$,

3 Alejandro SaAvedra PARra, «Estado chileno y legislación indígena», en Armando MARILEO, et al., ¿Modernización o sabiduría en tierra mapuche?. Santiago, Librería San Pablo, 1995, p. 171.

${ }_{4}^{4}$ Hasta esa fecha, los grupos Mapuches no habían sido sometidos y vivían en forma independiente en el territorio comprendido entre los ríos Bío-Bío y Toltén. Controlaban también las zonas Pampeanas y norpatagónicas transandinas como efecto del proceso de «araucanización de las Pampas». Para más información sobre los Mapuches durante el período colonial y republicano temprano véase : Guillaume BocCARA, Guerre et ethnogenèse mapuche dans le Chili colonial. L'invention
} 
de los indígenas. Entre 1884 y 1927, se entregaron títulos de merced a los longko (caciques) y se procedió a la delimitación de reducciones o reservas.

Esta política de radicación conoció un cambio radical a partir del segundo tercio del siglo XX. Se impulsó entonces la división de las comunidades indígenas con el fin de integrar definitivamente al Mapuche en la sociedad nacional chilena. El desarrollo económico, la educación, la capacidad y libertad contractual individual del indígena sobre su hijuela, constituyeron las herramientas de una nueva política que tuviera como meta «civilizar» definitivamente a los indígenas. Fue el inicio de una política que buscará, a través de la desorganización de las estructuras políticas y sociales autóctonas y vía la penetración de la lógica del libre mercado en las comunidades, una «solución definitiva» al problema indígena. Hace falta notar que desde el punto de vista del algunos representantes indígenas, la política implementada por la sociedad wingk ${ }^{5}$ no siempre fue percibida como peligrosa para la integridad cultural de la entidad mapuche. En efecto, algunos vieron en el acceso a la educación y a la libertad contractual la oportunidad de insertarse de manera positiva en la sociedad dominante cultivando su especificidad en el nuevo marco socio-histórico 6.

La Termination Policy chilena conoció una pausa durante el gobierno de la Unidad Popular. Entre 1970 y 1973, vía la reforma agraria, las tomas de terrenos y la promulgación de una nueva ley indígena, cerca de 100000 hectáreas fueron traspasadas a comunidades. Se crearon cooperativas indígenas, se intentó promover el desarrollo económico, social y cultural de los Mapuches y se buscó (con concepciones a veces ajenas a la lógica sociocultural autóctona) el fortalecimiento de la comunidad. Aquí también, conviene recalcar que la concepción etnocéntrica según la cual la economía mapuche representaba de alguna manera el prototipo del Modo de Producción Comunista Primitivo tenía poco que ver con la dinámica socioeconómica real de las «comunidades» indígenas ${ }^{7}$.

du Soi. Paris-Montréal, Éditions L'Harmattan, 1998; Martha BECHIS, Interethnic relations during the Period of Nation-State formation in Chile and Argentina: from Sovereign to Ethnic. Ann Arbor, University Microfilm International, Ph. D., 1984; Rolf FOERSTER, Jesuitas y Mapuches, 15931767. Santiago, Editorial Universitaria, 1996; Arturo LEIVA, El primer avance a la Araucanía: Angol 1862. Temuco, Ediciones Universidad de La Frontera, 1984; Leonardo LEON Solis, Maloqueros y conchavadores en Araucania y las Pampas, 1700-1800. Temuco, Ediciones Universidad de La Frontera, 1991 y The policy towards the Araucanian during the XVIII and XIX centuries in Argentina and Chile. University of London, Ph. D., 1991.

5 El no-mapuche.

6 Volveremos más adelante sobre la manera como la mayoría de los estudiosos tienden a adoptar marcos interpretativos y categorías que poco tienen que ver con la lógica y dinámica sociocultural autóctona. Veremos que el hecho de ignorar las percepciones, estrategias y categorías indígenas en el análisis de las políticas indígenas llevadas a cabo por el Estado chileno remite y determina en gran parte una concepción etnocéntrica y sustantivista de las sociedades y culturas estudiadas.

7 Para una crítica del enfoque etnocéntrico y esencialista adoptado en el estudio de la realidad mapuche histórica y contemporánea véase Guillaume BOCCARA; «Organisation sociale, guerre de captation et ethnogenèse chez les Reche-Mapuche à l'époque coloniale», en L'Homme (Revue 
El golpe de estado de septiembre 1973 y la implementación de una política económica neoliberal marcó una clara involución en el reconocimiento de los derechos autóctonos. Fue el periodo de liquidación de las comunidades. Legalmente, los indígenas desaparecieron del territorio nacional. A pesar del carácter objetivamente peligroso de tales medidas, muchos comuneros se conformaron con la entrega de títulos de propiedad individual. Ello, como veremos, no deja de plantear un problema en cuanto a la manera como los indígenas perciben y controlan las iniciativas provenientes del Estado wingka .

El último momento que consideraremos empieza en 1989 con la firma de un acuerdo entre las organizaciones mapuches y la Concertación de Partidos por la Democracia. Pareciera iniciarse entonces una nueva época en las relaciones entre el Estado y los pueblos autóctonos. Sin embargo, la promulgación de una nueva ley que reconoce y valora la diversidad cultural, la creación de la CONADI (Corporación Nacional de Desarrollo Indígena) como organismo intermediario entre el Estado y las etnias indígenas y la implementación de políticas interculturales en educación y salud, no siempre satisfacen las demandas indígenas. La complejidad de la realidad autóctona (diversidad sociocultural interna, falta de intermediarios adecuados al nuevo marco institucional de interrelaciones, importancia de la población indígena urbana, etc.) no ha sido captada por la nueva normativa. Queda por definir el contenido del nuevo concepto de etnodesarrollo y sobre todo queda por resolver el problema de la autodeterminación. De suerte que si los Mapuches ganaron últimamente en visibilidad y si ciertos derechos les fueron reconocidos, los debates acerca de la calificación de los autóctonos como sujetos del derecho (minoría étnica, pueblo o nación) y de las especificidades jurídicamente reconocidas, se encuentran en su etapa inicial.

Antes de iniciar nuestra presentación de las políticas indígenas chilenas queremos dejar en claro dos cosas que tienen que ver con el enfoque y la periodización adoptados en este artículo.

En primer lugar, analizar las políticas indígenas implementadas en Chile no significa atenerse a la presentación de las distintas leyes indígenas. De ahí que en este trabajo hagamos amplia referencia al contexto sociohistórico y a las ideologías imperantes en cada uno de los momentos distinguidos ${ }^{9}$.

En segundo lugar, hace falta notar que la periodización aquí determinada no corresponde necesariamente a la manera como los propios indígenas percibieron

\footnotetext{
Française d'anthropologie), $\mathrm{n}^{\circ}$ 150. Paris, 1999, pp. 85-118 y Roger Yvon KellnER, The Mapuche during the Pinochet Dictatorship. Clara Hall, University of Cambridge, Ph. D., 1993.

8 Una vez más conviene notar que la perspectiva antropológica (i. e. partir de las categorías, interpretaciones y estrategias indígenas) está ausente de la gran mayoría de los estudios sociojurídicos que tratan de la naturaleza y de los impactos de las políticas indígenas.

9 Así, tendremos que considerar los estereotipos que, expresando, justificando y determinando las distintas políticas indígenas, en cada época construyeron los criollos acerca del Mapuche: valiente guerrero, héroe, salvaje sangriento, flojo-ladrón-borracho, pobre-ignorante, etc.
} 
e interpretaron la historia. Si bien es cierto que el objeto de este artículo no es abordar el régimen de historicidad autóctono, haremos sin embargo alusiones a los desfases que existieron entre las aspiraciones y esperanzas de algunos agentes sociales wingka y las concepciones autóctonas respecto del ente estatal y de las iniciativas tomadas desde el exterior.

\section{LOS ALBORES DE LA REPUBLICA: LA POSTURA ARAUCANISTA Y LA CONS- TRUCCION DE LA CASA GRANDE (1810-1850)}

A pesar de las tentativas reiteradas de conquista y colonización de sus territorios por parte de los hispanocriollos durante la Colonia, los grupos Mapuches vivían todavía en forma independiente en el momento de las guerras de independencia (1810-1818). Mas aún, lejos de haber sido sometidos al yugo colonial, las sociedades indígenas del centro-sur de Chile salieron enriquecidas y potenciadas de esos tres siglos de contactos ${ }^{10}$. Demostrando una gran capacidad de adaptación e innovación, los antiguos guerreros Reche ${ }^{11}$ se habían transformado en hábiles conchavadores $^{12}$, maloqueros ${ }^{13}$ y negociadores. A través de reestructuraciones políticas, económicas y sociales considerables, habían logrado contrarrestar toda tentativa de sujeción por parte de los agentes coloniales y controlaban un espacio que unía los dos Océanos.

La resistencia que los indígenas opusieron a los Conquistadores y luego al ejército de Estado permanente desembocó, en el siglo XVII, en la formación de una zona fronteriza más o menos estable a lo largo del río Bío-Bío ${ }^{14}$. Frente al éxito militar indígena, las autoridades coloniales implementaron entonces una nueva política de sujeción. La mision y el parlamento llegaron a ser los dos pilares de la política colonial en esas tierras australes de un interés geopolítico cru-

${ }^{10}$ La conquista del sur de Chile empezó en 1550 bajo el mando del extremeño Pedro de Valdivia. En 1553, Valdivia fue capturado y ejecutado por los indígenas de la Araucanía. En 1598, el segundo levantamiento general, que costó la vida al Gobernador Martín García de Loyola, acabó con las siete ciudades españolas así como con la presencia hispánica al sur del Río Bío-Bío. Empezó entonces a configurarse la zona fronteriza de la Araucanía.

11 A la llegada de los peninsulares, los indígenas que habitaban los territorios situados entre los ríos Itata y Toltén se autodenominaban Reche, Gente $(C h e)$, auténtica, verdadera $(R e)$. En otros trabajos hemos mostrado cómo la etnia mapuche, que emerge en la segunda mitad del siglo XVIII, es en gran parte el producto de un proceso de etnogénesis y etnificación. Véase BocCARA [4].

12 De conchavo, comercio.

${ }^{13}$ De maloca, razzia o empresa económico-guerrera. Sobre este tema véase: LEON SOLIS [4]; Raúl MANDRINI, «La sociedad indígena de las Pampas en el siglo XIX», en Mirta LiSCHETTI (Comp.), Antropología. Buenos Aires, Editorial Universitaria, 1987, pp. 205-230.

14 Patricia CERDA-Hegerl, Fronteras del sur. La región del Bío-Bío y la Araucanía chilena, 1604-1883. Temuco, Ediciones Universidad de La Frontera-Instituto Latinoamericano de la Universidad Libre de Berlín, 1997.

R. I., $1999, \mathrm{n}^{\circ} 217$ 
cial para la Corona ${ }^{15}$. Esas dos instituciones tenían como meta vigilar y «civilizar» a los indígenas a través de la inculcación de la «verdadera cultura y religión» así como de la implementación de una norma jurídica común ${ }^{16}$. Pero a pesar de esta política plurifacética de normatización, los Mapuches seguían cultivando su especificidad, obedeciendo a una pauta cultural propia y velando por su independencia territorial.

Es en este panorama particularmente favorable a los indígenas que llegan las guerras de independencia. De manera global, se puede decir que el nuevo contexto no modificó sustancialmente, por lo menos en un primer momento, la lógica imperante en el espacio fronterizo sureño. Como lo señala Jorge Pinto, «el mayor interés de los gobiernos de esos años, se orientó a contener los focos de resistencia contra la independencia [...] y a establecer con los mapuche acuerdos que aseguraran la tranquilidad en la zona» ${ }^{17}$. A pesar de lo estéril que había resultado la política de pacificación española, las autoridades chilenas siguieron confiando en la evangelización y en los parlamentos ${ }^{18}$ como medios para integrar a los «valientes y bravos guerreros Araucanos». Primero porque el joven EstadoNación aún no necesitaba las tierras libres de la Araucanía. Segundo porque el

15 Leonardo LEON SOLIS, «Los Araucanos y la amenaza de ultramar, 1750-1807», en Revista de Indias, $\mathrm{n}^{\circ}$ 201. Madrid, CSIC, pp. 313-354.

16 Guillaume BOCCARA, «Notas acerca de los dispositivos de poder en la sociedad colonialfronteriza, la resistencia y la transculturación de los Reche-Mapuche del Centro-Sur de Chile (XVIXVIII), en Revista de Indias, n $^{\circ} 208$. Madrid, CSIC, 1996, pp. 659-695 y «El poder creador: tipos de poder y estrategias de sujeción en la frontera sur de Chile en la época colonial», en Anuario de Estudios Americanos, tomo LVI. Sevilla, Escuela de Estudios Hispanoamericanos, 1999, forthcoming; Carlos LAZARO AVILA, «El reformismo borbónico y los indígenas fronterizos americanos», en Agustín Guimera (Ed.), El reformismo borbónico. Madrid, Alianza Editorial, 1996, pp. 277-292 y «Parlamentos de paz en la Araucanía y las Pampas: una visión comparativa (1604-1820)», en Memoria Americana. Cuadernos de etnohistoria, $\mathrm{n}^{\circ} 7$. Buenos Aires, Universidad de Buenos Aires, 1998, pp. 29-60; FOERSTER [4]; Luz María MENDEZ BELTRAN, «La organización de los parlamentos de indios en el siglo XVIII», in Sergio VILlaLOBOS, et al., Relaciones fronterizas en la Araucanía. Santiago, Ediciones Universidad Católica, 1982, pp. 107-173; Horacio ZAPATER, La búsqueda de la paz en la guerra de Arauco : Padre Luis de Valdivia. Santiago, Editorial Andrés Bello, 1992; JoséManuel ZaVALA, «L'envers de la «Frontière» du Royaume du Chili», en Histoire et Sociétés de l'Amérique Latine, $\mathrm{n}^{\circ}$ 7. Paris, 1998, pp. 185-208.

17 «Integración y desintegración de un espacio fronterizo. La Araucanía y las Pampas, 15501900», en Jorge PINTO RodrigueZ, (Ed.), Araucanía y Pampas. Un mundo fronterizo en América del sur. Temuco, Ediciones Universidad de La Frontera, 1996, p. 35.

18 Los parlamentos, que contribuyeron a formar en la frontera un «ámbito de consenso» (LAZARo AvILA, 1998 [16]), reconocen en sus actas la existencia de «Naciones Indias» al sur del río Bío-Bío. Estos tratados, firmados entre dos pueblos, y que por lo tanto fundamentan la existencia de los pueblos autóctonos como sujetos soberanos del derecho internacional, se convirtieron últimamente en un enjeu de envergadura. Revivificados por nuevas lecturas, representan una potente arma jurídica en manos de las organizaciones indígenas : «Magia de la interpretación jurídica que transforma el despojo en redención» (Norbert Rouland, et al., Droit des minorités et des peuples autochtones. Paris, PUF, 1996, p. 347).

R. I., 1999, $\mathrm{n}^{\circ} 217$ 
indígena, convertido en símbolo nacional de la resistencia a la vieja colonia, era visto de algún modo como el aliado natural de los libertadores. El hecho de que los Mapuches se hubieran puesto preferentemente del lado del bando realista no era aún visto como una traición sino más bien como un desconocimiento de su propio destino histórico. El poco interés que despertaba en los indígenas el proyecto emancipador, no parecía desalentar el espíritu integracionista de los padres de la Patria. Los Araucanos, «lustre de la América», formaban una preciosa porción de Chile, afirmaba O'Higgins en $1817^{19}$. Es en base a los mismos principios liberales que inspiraban la independencia que se dictó en 1819 un bando supremo en el que se considera a los indígenas «ciudadanos chilenos y libres como los demás habitantes del Estado» ${ }^{20}$. Pocos años antes, en 1813, la Junta de Gobierno ponía fin a los denominados Pueblos de Indios, instando a los indígenas a residir desde ahora en Villas Formales. Se trataba, pues, «de valorar al mapuche e incluirlo en la nación que se estaba fundando, para construir con él y sus territorios el nuevo país que surgía de las ruinas del mundo colonial» ${ }^{21}$. Por lo tanto, no es de extrañarse que después de los primeros sobresaltos de las guerras de independencia $^{22}$, las autoridades hayan reanudado la política tradicional de civilización de los indígenas vía la misión y el parlamento.

Durante el parlamento de Yumbel de 1823, se reafirmó el principio de la integración ciudadana de todos los habitantes del territorio chileno, desde Atacama hasta Chiloé. Una década después se reestableció el Colegio de Propaganda Fide de Chillán ${ }^{23}$, pilar de la obra misional en la Araucanía colonial después de la expulsión de los Jesuitas en 1767. En 1837 volvían, en un Chile desde ahora independiente, los primeros doce misioneros franciscanos encargados de la labor de evangelización, es decir de civilización, sedentarización e integración de los indígenas a esta nueva «casa grande» que se estaba construyendo. En 1848, las autoridades chilenas asignaron a los Capuchinos italianos la tarea de evangelizar y educar a los indígenas ubicados al sur del río Cautín. Indudablemente, la fuerza

19 Citado por Jorge PINTO RodRigueZ, «La Araucanía, 1750-1850. Un mundo fronterizo en Chile a fines de la Colonia y comienzos de la República», en Jorge PinTo RodRIGUEZ, (Ed.), Modernización, inmigración y Mundo Indígena. Chile y la Araucanía en el siglo XIX. Temuco, Ediciones Universidad de La Frontera, p. 28.

${ }^{20}$ Citado por Hugo ORMEÑO \& Jorge OSSES , «Nueva legislación sobre indígenas en Chile», en Cuadernos de la Realidad Nacional, $\mathrm{n}^{\circ}$ 14. Santiago, Universidad Católica de Chile, 1972, p. 18.

21 PinTo Rodriguez [19], p. 29.

22 En los años 1820, la Araucanía, la zona cordillerana y las Pampas se transformaron en espacios inestables en los cuales actuaron las famosas montoneras. Ahí, indígenas, ex-realistas y «bandidos» se enfrentaron a las nuevas autoridades en una contienda que la historiografía tradicional calificó de «Guerra a Muerte». Sobre este tema véase: Benjamín ViCUÑA MACKENNA, La Guerra a Muerte. Buenos Aires, Editorial Francisco de Aguirre, 1972.

23 Véase Jorge PinTo RoDRIGUEZ, «Al final de un camino. El mundo fronterizo en Chile en tiempos de Balmaceda», en Revista Complutense de Historia de América, $\mathrm{n}^{\circ} 22$. Madrid, Universidad Complutense de Madrid, 1996, pp. 287-322. 
no era el camino elegido para asimilar a los que eran considerados aún como los precursores del destino nacional.

Tal como lo señala con mucho acierto Jorge Pinto, «el estado, que involucra territorio y población, fue pensado en Chile, desde el punto de vista territorial, como una casa que debía construirse con el esfuerzo de todos los pobladores que lo habitaban [...] y desde el punto de vista de la población, como una hermandad o gran familia [...] la nación política, sujeta a las normas que dentro de la casa impondrían las autoridades del país» ${ }^{24}$.

Ahora bien, si el contexto ideológico no parecía aún tan desfavorable para los indígenas, es porque los grupos dirigentes habían orientado tempranamente sus preocupaciones hacia el Valle Central (agricultura) y el Norte (minas). De hecho, a pesar de que el joven estado chileno emergió mirando hacia el Norte ${ }^{25}$, los proyectos de conquista territorial y de adelantamiento de la línea fronteriza sureña no desaparecieron del todo ${ }^{26}$. De suerte que la continuación de la política indígena colonial aparece como una solución de espera en pos de la total anexión territorial de la Araucanía. Tres elementos permiten confirmar esta hipótesis. En primer lugar, las normativas de 1823 y 1830 constituyeron la primera tentativa de imponer el dominio estatal sobre terrenos indígenas así como la supremacía del sistema jurídico chileno ${ }^{27}$. En segundo lugar, empezó a materializarse la idea de traer a inmigrantes europeos para colonizar la región con «hombres laboriosos» ${ }^{28}$. $\mathrm{El}$ proyecto de inmigración selectiva como manera de «mejorar la raza chilena» ya se concretó con la ley de colonización dictada por el presidente Bulnes en

24 Pinto Rodriguez [19], p. 34, n. 48.

25 «Chile inicia su historia republicana mirando hacia el norte. En su caso, la articulación de su economía a los circuitos del capitalismo decimónico pasaba por la aceleración de la producción minera del Norte Chico. Hacia allá se orientaron las inversiones inglesas, el interés de los empresarios locales y de las autoridades de gobierno. El propio Portales intentó, pocos años después de la Independencia, establecer en las cercanías de Valparaíso una planta refinadora de cobre que permitiera procesar un metal que significaba tanto para el país como las lanas para Argentina» (PINTO RODRIGUEZ [17], p. 41).

26 «Puedo aseguerar a V. S. -escribía el general Bulnes al presidente Joaquín Prieto en 1833, refiriéndose a los mapuche- que están tan abatidos y tan domado su antiguo orgullo, que sin el menor inconveniente podríamos avanzar nuestra insignificante línea de frontera al otro lado del Bio Bio, y aún reedificar las principales ciudades arruinadas que habían en sus terrenos, si la República tuviese habitantes y recursos para hacerlo», citado por PINTO RodRIGUEZ [19], p. 43.

27 «Ley de 10 de junio de 1823 y Decreto de 28 de junio de 1830 , que ordena a los intendentes nombren un vecino para que «se instruya de los pueblos de indígenas que existan o hayan existido en su provincia», a fin de que se midan, tasen y rematen los terrenos sobrantes pertenecientes al Estado. La ley mencionada dispuso, en el artículo $3^{\circ}$, «Que lo actual poseído según ley por los indígenas se les declare en perpetua y segura propiedad»», citado por ORMEÑO \& OSSES [20], p. 18.

${ }_{28}$ Carmen NorambUENA, «La Araucanía y el proyecto modernizador de la segunda mitad del siglo XIX. ¿Exito o fracaso?», en Jorge Pinto RodrigueZ, (Ed.), [19], pp. 227-257; PinTo RODRIGUEZ [18], pp. 45-46.

R. I., 1999, n. ${ }^{\circ} 217$ 
1845 ${ }^{29}$. En tercer lugar, la integración económica de la región del Bío-Bío al resto del territorio de Chile ya había empezado en los años 1830-1840 ${ }^{30}$. La demanda de productos agrícolas de las regiones mineras nortinas así como, a partir del año 1848 , de California determinaron profundos cambios en la sociedad fronteriza sureña. La formación de latifundios y de numerosas sociedades de accionistas en la región del Bío-Bío representaron el preludio de la colonización del territorio de la Araucanía. Del mismo modo, el inicio de la explotación carbonífera en la zona costera (Coronel, Lota, Lebu, Arauco) significó la penetración progresiva de grandes comerciantes en tierras tradicionalmente indígenas ${ }^{31}$. Poco faltaba antes de que la conquista y colonización de este «enclave salvaje e improductivo en territorio nacional» se transformara en unas de las prioridades del Estado. El proindigenismo de los primeros tiempos iba a ser desplazado por un discurso antiindigenista, evolucionista y racista, que legitimara las usurpaciones y violencias legales y privadas de toda índole.

\section{INDIOS MALOS EN TIERRAS BUENAS ${ }^{32}$ : DINAMICA DE COLONIZACION Y CONQUISTA MILITAR DE LA ARAUCANÍA (1852-1883)}

El proceso histórico que condujo a la derrota final de los Mapuches como entidad independiente y soberana para convertirlos en una minoría étnica sometida a una opresión combinada (económica, política, cultural) remite a dinámicas múltiples que se conjugaron y conspiraron en la misma dirección. La instauración de la hegemonía nacional chilena no fue únicamente el resultado de una conquista por las armas ${ }^{33}$ ni tampoco el producto lógico de la asimilación sin tropiezos de los indígenas a través de los mecanismos fronterizos de la convivencia pacífica $^{34}$. Como veremos ahora, existen mecanismos mucho más sutiles de im-

29 Norambuena [28], p. 231.

30 CERDA-HegerL [14], pp. 107-124.

31 CERDA-Hegerl [14], pp. 120-124.

32 Retomamos aquí el título de un artículo de Fernando CASANUEVA, «Indios malos en tierras buenas. Visión y concepción del mapuche según las élites chienas del siglo XIX», en Jorge PINTO RODRIGUEZ (Ed.) [19], pp. 55-131.

33 Aunque la mal llamada «pacificación de la Araucanía» representó un enorme traumatismo para los grupos mapuches y quedó como un hecho negro en la memoria colectiva indígena, cometeríamos un error en reducir la imposición de la dominación chilena en la Araucanía a un hecho de conquista guerrera. Para más detalles sobre el proceso multifacético de conquista y colonización véase José BENGOA, Historia del pueblo Mapuche (siglos XIX y XX). Santiago, SUR Ediciones, 1985.

34 Idea que ha venido sosteniendo desde 1980 el historiador chileno Sergio Villalobos en sus diversas publicaciones. Para un análisis crítico del enfoque del jefe de fila de los Estudios Fronterizos véase: Eugenio ALCAMAN, «La historia y la antropología en la etnohistoria mapuche», en Roberto MORAlES U., (Comp.), Universidad y pueblos indígenas. Temuco, Instituto de Estudios Indígenas, 1997, pp. 110-127; BOCCARA [4], pp. 179-200; Rolf FOERSTER \& Jorge Iván VERGARA,

R. I., $1999, \mathrm{n}^{\circ} 217$ 
posición paulatina de un orden exterior. Las dinámicas históricas transcienden muy a menudo las conciencias de los agentes sociales y si bien los individuos saben lo que hacen y por qué lo hacen, pocas veces anticipan con acierto las consecuencias de lo que hacen. De suerte que las acciones e intereses inmediatos de los agentes sociales pueden producir efectos perversos que, a la larga, jugarán en contra de ellos. Tal es el caso, por ejemplo, de los caciques que arrendaron, regalaron o vendieron tierras a oficiales, comerciantes y colonos en un momento en que no se percibía aún la fuerza arrolladora de la nueva dinámica económica y política nacional e internacional. Algunas décadas más tarde, vía el despojo legal por imposición del sistema jurídico occidental y de una concepción diferente de la tenencia y apropiación de la tierra, vía la vinculación de la economía regional con los mercados internacionales, vía la conquista por las armas y vía la instauración de un ideal modernizador productivista, esos mismos indígenas se encontrarían trabajando sus antiguas tierras como arrendatarios, inquilinos o peones. Es a través del análisis de esos múltiples factores y dinámicas que se entrelazan y potencian (la colonización económica, la imposición de una normativa estatal, la conquista militar, el ideal de progreso) que enfocaremos lo que fue el ocaso del pueblo mapuche como entidad independiente y soberana ${ }^{35}$.

Si dirigimos nuestra mirada hacia la evolución económica de la región sureña, constatamos que la dinámica de expansión que arrancó en las décadas anteriores tendió a acentuarse. La colonización espontánea, es decir no impulsada desde el Estado, se dio en múltiples frentes y revistió distintas formas. La explotación de carbón en la franja costera de la Araucanía conoció un crecimiento rápido ${ }^{36}$. Los mismos comerciantes que, aprovechándose de la demanda exterior en trigo y harina habían participado en la colonización de tierras indígenas del norte de la Araucanía, invertieron en la década del 50 en la compra y arriendo de terrenos indígenas en los cuales existían mantos carboníferos. Si sumamos a esto que «la demanda de harina de California fue cubierta entre 1848 y 1860 mayori-

\footnotetext{
«Relaciones interétnicas o relaciones fronterizas?», en Revista de Historia Indígena, $\mathrm{n}^{\circ} 1$. Santiago, Universidad de Chile, 1996, pp. 9-33.

${ }_{35}$ Muchas veces, los estudios jurídicos sobre políticas indígenas olvidan que detrás del velo normativo es necesario identificar actores, estrategias, ideologías dominantes y contextos históricos. Para un excelente análisis de los derechos de los pueblos autóctonos en términos globales véase ROULAND, et al. [18]. La misma crítica vale para los estudios históricos que tienden a ignorar el marco legal que sin embargo viene a ratificar y reforzar la dinámica de despojo y la perspectiva hegemónica y etnocéntrica dominante. Como lo demuestran los trabajos de Patricia Cerda-Hegerl [14], Jorge Pinto Rodríguez [19] y, en cierta medida, de Wilson Cantoni («Relaciones del mapuche con la sociedad nacional chilena», en Relaciones interétnicas en Bolivia y Chile. Santiago, Escuela Latinoamericana de Sociología, 1972, pp. 227-332), sólo una perspectiva global y interdisciplinaria permite tomar la medida de la empresa polimorfa de colonización y conquista de los pueblos autóctonos.

36 Patricia Cerda-Hegerl señala que el volumen de la producción total de carbón en la zona costera septentrional de la Araucanía pasó de 6.438 toneladas en 1852 a 565.000 en 1880 (véase CERDA-HegerL [14], p. 123).
}

R. I., 1999, n. $^{\circ} 217$ 
tariamente por la producción de la región del Bío-Bío» ${ }^{37}$, podemos entrever la presión que se ejerció durante esos años sobre las tierras indígenas sureñas. Como consecuencia de este crecimiento económico, llegaron a la región las tecnologías modernas: primeras máquinas trilladoras en 1857, planta telefónica y ferrocarril en la zona de Lota en 1881. Las oportunidades de enriquecimiento en la región atrajeron numerosos inversionistas y mano de obra. En 1855, se registra una cifra de aproximadamente 13.000 no-mapuche entre los ríos Bío-Bío y Malleco, es decir más allá del límite fronterizo histórico. En la zona costera, son 14.000 personas que se instalaron como consecuencia de la explotación de carbón ${ }^{38}$.

Contemporáneamente a este proceso de penetración espontánea, el Estado dictó varias normativas que, a pesar de su aspecto regulador y aparentemente protector de los intereses indígenas, tendieron a reforzar la dinámica anexionista y de colonización agrícola.

Es así como la ley de 1835 sobre denuncios de tierras baldías permitió la adquisición de grandes extensiones de terrenos en la Isla de la Laja. Esta ley, como las normativas posteriores, desconociendo totalmente el sistema de tenencia y ocupación de tierras por parte de los indígenas, permitía al denunciante apropiarse de un terreno juzgado libre de propietario. Como lo señala Cerda-Hegerl, son los mismos actores fronterizos (capitanes de amigos, oficiales del ejército) los que se aprovecharon de esta normativa para apropiarse de las tierras que tradicionalmente habían hecho parte del espacio económico-territorial potencial de los indígenas ${ }^{39}$.

Por otra parte, el Estado dictó una ley de colonización en 1845 sentando las bases de la futura llegada de colonos extranjeros. Tal como lo señala Carmen Norambuena, las autoridades y las élites sostenían un ideario centrado en dos aspectos: la civilización y el progreso por una parte, la utopía agraria por el otro $^{40}$. El primero enunciaba que el contacto con gentes civilizadas europeas provocaría la transformación de las «deficientes costumbres» de la gente de la frontera. El segundo, fundamentado en la idea productivista según la cual una tierra que no está trabajada «racionalmente» y en forma continua es una tierra baldía, sostenía «la urgencia que tenía el país de poner en producción grandes espacios

37 Cerda-Hegerl [14], p. 113.

38 CERDA-Hegerl [14], p. 130.

39 Ello ilustra la manera como los múltiples dinámicas se reforzaban mutuamente y conspiraban en una misma dirección : la anexión de las tierras indígenas a través de la colonización espontánea, de la conquista por las armas, de las normas legales y del discurso estigmatizador sobre el Indio. Prototipo de la cojunción, a nivel individual, de esos varios resortes de la acción es la persona de Cornelio Saavedra : comandante en jefe del ejército de operaciones en territorio araucano, diputado, administrador de los bienes del riquísimo comerciante José Ignacio Palma, principal artífice de la «pacificación de la Araucanía», promotor de la colonización extranjera en la zona y jefe de fila de los que denunciaban la «barbarie indígena».

40 NORAMBUENA [28], p. 230. 
territoriales que se presentaban como verdaderos «desiertos demográficos»» ${ }^{41}$. Como consecuencia directa de esta ley se instalaron colonos alemanes en la Isla de la Laja y en las provincias del sur chileno (Valdivia, Osorno). En los años 1880 , son casi 7.000 colonos del viejo continente que se establecieron en la Araucanía. Terminada la conquista por las armas, vendrían el segundo plan de colonización y la urbanización acelerada de los antiguos «territorios indios».

Con las leyes de denuncios de 1835 y de colonización de 1845 , se inicia una política que tiende a apagar la soberanía autóctona a través de diversas decisiones y medidas legislativas unilaterales que ya no consideran los acuerdos pasados durante los parlamentos republicanos. Es así como en 1852, asestando otro golpe a la soberanía indígena, se crea por ley la Provincia de Arauco ${ }^{42}$. Esta comprende en su demarcación «los territorios de indígenas situados al Sur del Bío-Bío y al Norte de la provincia de Valdivia». La integración administrativa iba a buen paso.

Finalmente, los contratos de compraventa, arriendo, cesión de derechos involucrando a mapuches sirvieron para traspasar a manos criollas, vía la ley de 1866, vastos territorios indígenas ${ }^{43}$. La ley de 4 de diciembre 1866 marca un hito en la política de despojo legal. Contempla el deslinde, por una comisión de ingenieros, de los terrenos pertenecientes a indígenas y declara baldías y, consiguientemente, propiedad del fisco las tierras sobre las cuales no se puede probar la ocupación efectiva y continuada de un año. Como lo señala un estudio sobre legislación indígena: «Este es el origen de la Comisión Radicadora y de los Títulos de merced. [...] Mediante la aplicación de esta norma [sobre tierras baldías] la Comisión Radicadora que operó con posterioridad fue privando a los indígenas de la mayor parte de sus suelos. Bastaba para ello con no tener por probada la posesión efectiva y continuada a lo menos de un año sobre los terrenos que realmente ocupaban los mapuches. La misma ley dispone que «los terrenos que el Estado posea actualmente y los que en adelante adquiera se venderán en subasta pública en lotes que no excedan de quinientas hectáreas», pagándose el precio en cincuenta anualidades iguales, sin intereses. En suma, la ley de 4 de diciembre de 1866 facilitó la apropiación de las tierras de indígenas, tanto por el Estado como por los particulares» ${ }^{44}$.

La estrategia legal de colonización iba, a partir de esa fecha, a combinarse con la conquista militar. En el año 1862, empieza, en un clima cada vez más antiindígena, la llamada «pacificación de la Araucanía». La línea de frontera avanza desde el Bío-Bío hasta el Malleco. El jurista chileno José Aylwin describe en esos términos el plan de conquista del territorio indígena ideado por el Coronel

\footnotetext{
41 NoRAmbuena [28], p. 230.

42 ORMEÑO \& OSSES [20], p. 18.

43 Patricia Cerda-Hegerl insiste sobre la manera como los agentes fronterizos aprovecharon las buenas relaciones que tenían con algunos grupos indígenas para comprar, recibir en donación o arrendar terrenos (CERDA-HEGERL [14], pp. 120-121 y pp.127-131).

44 ORMEÑO \& OSSES [20], pp. 18-19.
} 
Cornelio Saavedra: «En 1861 por encargo del gobierno, éste [Saavedra] delínea un plan de ocupación gradual de la Araucanía que el mismo año será presentado al Congreso. Su plan, en síntesis, consistía en el adelantamiento de la línea fronteriza hasta el río Malleco, línea que sería protegida con la construcción de una serie de fuertes, dejando como territorio mapuche independiente aquel comprendido entre el Malleco y el Toltén; la subdivisión y posterior enajenación de los terrenos del Estado comprendidos entre el Bío-Bío y el Malleco; y en la colonización por extranjeros de los terrenos de la Araucanía» ${ }^{45}$. En este plan regulador impulsado por el Estado, que tenía como objetivo controlar la colonización espontánea que se había dado hasta el momento, el ejército jugaba un papel central. La mecánica de despojo legal apoyado en la fuerza militar y determinado por la nueva dinámica económica indujo lógicamente la merma del territorio indígena. El mismo Saavedra afirmaba: «El Estado puede entrar a enajenar ventajosamente las grandes extensiones de terrenos baldíos que existen entre dicho río [el Malleco] y el Bío-Bío. Se puede estimar en no menos de 500 mil hectáreas los terrenos comprendidos entre los ríos mencionados, el Vergara y la montaña que está al pie de la cordillera de los Andes. De esta porción permanecerán 200 mil hectáreas a propietarios civilizados, 50 mil a los habitantes indígenas y el resto debe considerarse baldío y por consiguiente de propiedad del Estado» ${ }^{46}$.

No fue este el periodo más sangriento de la famosa guerra de pacificación puesto que la labor fraudulenta de numerosos especuladores, las ventas al fisco, las donaciones y arriendos de terrenos y la penetración espontánea diezmaron gran parte del territorio indígena por conquistar. Sin embargo la última fase de la ocupación de la Araucanía había comenzado. Se fundaron fuertes en lugares estratégi$\cos ^{47}$, un ejército compuesto por 7.000 hombres comenzó a avanzar legitimado en su acción por la ideología racista que se había impuesto entre la élite chilena.

En efecto, ya no se trataba de establecer relaciones comerciales o alianzas políticas con los indígenas. El objetivo era desde ahora conquistar el territorio aún libre, fijar las poblaciones indígenas en reservas, despejar terrenos para los nuevos colonos e incentivar la explotación «racional» del suelo en oposición a las prácticas económicas «anti-productivas» de los autóctonos. Política propiamente

45 José AYLWIN, Estudio sobre tierras indígenas de la Araucanía: antecedentes históricolegislativos (1850-1920). Temuco, Instituto de Estudios Indígenas, 1995, p. 17. Este plan de avance progresivo de la línea fronteriza recuerda la estrategia de conquista planeada por el Gobernador Alonso de Ribera en los primeros años del siglo XVII (sobre este tema véase Carlos LAZARO AVILA, La transformación sociopolítica de los Araucanos (siglo XVII). Madrid, Tesis del Departamento de Antropología de España y América, CSIC, 1995).

${ }^{46}$ Diputado Cornelio Saavedra, «Sesión de la Cámara de Diputados del 9 de agosto de1868», citado por CASANUEVA [32]; p. 100.

47 Zona costera: Lebu (1862), Cañete (1868) y valle central: Nueva Angol (1862), Mulchén (1862), Lolenco (1867), Collipulli (1867) (citado por CASANUEVA [32], p. 100). Aylwin señala que para 1868, «un total de ocho fuertes habían sido instalados a lo largo del río Malleco, emplazados a una legua de distancia el uno del otro» ([45], p. 18). 
etnocidaria que venía a negar toda posibilidad de soberanía de los indígenas sobre sus propios territorios. Las antiguas instituciones fronterizas (comercio, parlamento) y con ellas la dinámica del antiguo espacio fronterizo habían muerto. Los «hordas de salvajes sangrientos» no pueden ser consideradas como comunidades políticamente organizadas, pensaban las autoridades, y por lo tanto un Estado civilizado no puede contractar con ellas. En este contexto, los grupos indígenas perdían toda existencia jurídica y debían acatar las leyes superiores del Estado-Nación chileno: «La Cámara sabe que nuestra Constitución política determina que los límites de Chile son: por el norte el desierto de Atacama, al oriente la cordillera de los Andes, por el sur el cabo de Hornos y al poniente el mar Pacífico. Esto significa claramente que dentro de esos límites no puede haber nadie que no obedezca en todo las leyes de Chile», afirmaba en 1868 el ministro de Hacienda Vicente Reyes. Proseguía en esos términos: «Los ciudadanos y los extranjeros tienen la obligación de obedecer las leyes de Chile so pena de incurrir en los castigos que ellas señalan a la infracción. Si esto es cierto; si tampoco puede desconocerse que hay una fracción de habitantes en nuestro territorio que se llama araucanos, pero que para mí son también chilenos, ¿en virtud de qué derecho se les quiere eximir de la obediencia a nuestras leyes? [...] ¿Es o no un hecho que hay en Chile habitantes que no reconocen nuestra autoridad, ni ejercen uno solo de los actos de la vida civilizada, y que no tienen nuestra religión? Es cierto. Chile no debe soportar eso sin mengua de su dignidad y de su nombre ${ }^{48}$. En conformidad con la doctrina dominante de la época, los juristas chilenos sostenían que los únicos derechos territoriales válidos eran los existentes en el seno de las sociedades organizadas según las formas políticas modernas, las del Estado. En un contexto en que el evolucionismo se había impuesto como ideología dominante, los «pueblos civilizados» tenían el deber de hacer caso omiso de los derechos de los «salvajes». Debían combatir la «barbarie», como lo dice el ministro Reyes o dominar por la fuerza esa «raza salvaje y perversa», «de vil naturaleza», que posee «una crueldad congenital y horripilante» como lo pregonaba en un discurso lleno de odio el diputado e historiador Benjamín Vicuña Makenna ${ }^{49}$. La prensa (El Mercurio, El Ferrocarril) alimentaba la imagen de un indígena «im-

\footnotetext{
48 Sesiones de la Cámara de Diputados, Santiago, agosto de 1868, citado por CASANUEVA [32], p. 102.

49 Citado por Casanueva [32], p. 103. Raras e impotentes, pero no menores (Fr. Bilbao, J.V. Lastarria, M.A. Matta, J. Ateaga, P. Ruiz Aldea), fueron las voces que se alzaron en contra de esta política racista de civilización por las armas. Pero, «pese a las divergencias, hay que subrayar que todos los intervinientes [a la sesión de la Cámara de diputados del 8 de agosto de 1868] definen al indio como salvaje o bárbaro frente a la República civilizada. Todos están de acuerdo en la ocupación del territorio mapuche, sea por medios violentos o pacíficos» (CASANUEVA [32], p. 108). Sobre este tema véase CASANUEVA [32] y Jorge PINTO RODRIGUEZ, «Del antiingenismo al proindigenismo en Chile en el siglo XIX», en Jorge PINTO RodRIGUEZ, (Ed.), Del discurso colonial al proindigenismo. Ensayos de historia latinoamericana. Temuco, Ediciones Universidad de La Frontera, 1996, pp. 85-117.
} 
permeable a la empresa de civilización», de una sociedad autóctona hecha de «hordas de indios ladrones indómitos» ${ }^{50}$. Estamos lejos de la época en que los patriotas ensalzaban la imagen del «guerrero araucano bravo y precursor del destino nacional». El estereotipo del indio sangriento y traicionero se había impuesto. Las mentalidades estaban preparadas para el golpe final.

Entre 1870 y 1878, la línea de frontera avanzó hasta Traiguén. Una vez terminada la guerra del Pacífico, la segunda etapa de ocupación del territorio indígena, la última y la más violenta, se desarrolló entre los años 1881 y 1883 . La campaña militar, que bajo muchos aspectos se parece a las antiguas malocas hispanocriollas del siglo XVII (cosechas y ranchos quemados, ganado robado, mujeres y niños tomados prisioneros), se acabó en 1883 con la refundación de la ciudad precordillerana de Villarrica. La singular resistencia de los Mapuches había terminado. Los principios que dominaban la doctrina jurídica en la época clásica (igualdad jurídica, universalidad, autodeterminación) ${ }^{51}$ y que las autoridades coloniales y republicanas tempranas habían sido constreñidas a respetar en razón a la resistencia indígena habían sido desplazados por el nuevo discurso positivista y modernizador.

Se abría entonces una nueva etapa, la radicación y la integración de los Mapuches como minoría étnica y pueblo derrotado al Estado-Nación chileno.

\section{LA COLONIZACION INTERNA: REGULACION ESTATAL, RADICACION INDIGENA Y MARGINACION SOCIOHISTORICA (1883-1927)}

Existe una continuidad a nivel de las normativas entre el periodo anterior a la ocupación definitiva de la Araucanía y los años post-pacificación. Empero, si la ley de 1866 ya establecía mecanismos de radicación de los indígenas, deslindes de terrenos por parte de una comisión de ingenieros, regulación de la colonización espontánea y apropiación por el fisco de las tierras consideradas baldías, no es sino a partir de los años 80 que estas medidas se aplicarán en toda su magnitud y sobre la casi totalidad de la Araucanía histórica ${ }^{52}$. Inmediatamente obtenido el sometimiento mapuche, las autoridades tomaron disposiciones tendiendo a afianzar la ocupación de las tierras conquistadas y establecieron el marco jurídico e institucional en el cual se regularían las relaciones entre el Estado, los particulares y los indígenas durante más de cuatro décadas.

De manera general se puede decir que la política indígena del Estado en las primeras décadas post-pacificación se limitó al asunto territorial. De hecho, las

\footnotetext{
50 Casanueva [32].

51 Rouland, et al. [18], pp. 360-361.

52 Para más detalles sobre las múltiples normativas que se dictaron con el fin de, por una parte, proteger a los indígenas de las adquisiciones por particulares y por otra parte, otorgar al Estado el control de las ocupaciones, véase AYLWIN [45], pp. 23-31.
} 
distintas normativas no buscaron establecer relaciones con los indígenas ni implementar programas tendiendo a su incorporación a la sociedad nacional. La preocupación de las autoridades, en esta zona recién conquistada, era delimitar esferas de influencias entre el Estado y los particulares. Esta obra de normalización y de organización del dominio estatal en la frontera sureña hizo que, en alguna medida, los indígenas no fuesen los verdaderos destinatarios de las distintas leyes. Tal como lo escribe Mylene Valenzuela: «la legislación que se dictó [...] se dirigió a solucionar el problema de la propiedad indígena, a reglamentar su adquisición, la celebración de los contratos, la concesión de derechos reales, deslindamiento, fundación de poblaciones y colonias, radicaciones, etc. En síntesis, el objeto de la regularización legal se centró únicamente en la ocupación, distribución, transferencia y delimitación de la propiedad inmueble indígena»53.

$\mathrm{Al}$ abordar con normas de excepción la sóla cuestión de la terratenencia mapuche, la legislación dejaba los otros ámbitos del funcionamiento de la sociedad mapuche (herencia, delitos, obligaciones, etc.) bajo la reglamentación del Código Civil (1857). Ello venía a negar por omisión toda validez al derecho consuetudinario indígena e ignorar la particularidad cultural de los pueblos autóctonos. Los Mapuches, derrotados, se transformaron en objeto del derecho ${ }^{54}$ y perdieron rápidamente toda visibilidad en un Estado-Nación que daba por sentado que el proceso de chilenización se iba a dar sin tropiezos ${ }^{55}$. Así, la derrota militar, la estatización de los mecanismos de funcionamiento sociopolítico, la política de urbanización y la presión ejercida por los nuevos poderes regionales tuvieron consecuencias dramáticas para los grupos mapuches. Constreñidos a radicarse en reducciones que abarcaron apenas el $6 \%$ de su territorio histórico, los autóctonos fueron sometidos a un proceso de campesinización y de pauperización.

${ }^{53}$ Mylene VAlEnZuela, La legislación mapuche y la política indígena del Estado chileno. Santiago, Tesis, Universidad de Chile, 1992, p. 47.

${ }^{54}$ En relación a las normativas que tenían como objetivo proteger a los indígenas de los abusos de los particulares, Mylene VALEnZuela [53] escribe: «[...] los intereses y objetivos primordiales de las normas cautelares y prohibitivas establecidas por la ley y [...] los beneficios producidos en la propiedad indígena fueron tangenciales e indirectos, obtenidos como consecuencia de la protección que brindó el Estado a su política de colonización» (p. 51). De hecho, la política del Estado en esa zona fronteriza se caracteriza por el afán de proteger y reinvindicar sus derechos de la arremetida particular. De suerte que, como lo escribe la misma autora, «la constitución de la propiedad indígena fue un producto de la política de colonización dirigida por el Estado» ([53], p. 53) y la radicación tendió a crear exclusivamente «un área de «reserva vital»» ([53], p. 54).

55 En una entrevista realizada en 1993, el historiador mapuche Pedro Marimán dice: «Si uno mira desde una perspectiva histórica, nacional o étnica, nosotros somos un pueblo derrotado militarmente. Fuimos anexados como población y territorio al Estado chileno. Esa anexión nos significó la pérdida de nuestra base material de desarrollo [...]. Con la derrota perdimos también el territorio, y hoy sólo nos quedan tierras. Perdimos la masa ganadera que era la base económica de nuestro pueblo y hemos sido obligados a convertirnos en campesinos. Hemos vivido una suerte de colonialismo interno que ha ejercido el Estado chileno sobre los mapuches, sobre nuestros hermanos» (en SAAVEDRA PARRA [3], p. 184). 
Tres eran los ejes de acción definidos en la nueva ley de 20 de enero de 1883 : la radicación de indígenas, la enajenación de tierras fiscales en pública subasta y el otorgamiento gratuito de terrenos a colonos extranjeros y nacionales por el Estado $^{56}$. En cuanto al primer punto, la Comisión Radicadora de indígenas otorgó, entre 1884 y 1920, un total de 2.919 títulos de merced, sobre 526.285 hectáreas de terreno, para 83.170 personas. Vastas zonas de las provincias (Valdivia, Osorno, LLanquihue, Alto Bío-Bío) no recibieron la visita de la comisión y quedaron sin títulos ${ }^{57}$. Al terminarse el proceso de radicación los Mapuches, quienes antiguamente poblaban un territorio de aproximadamente diez millones de hectáreas (Arauco por el norte, Llanquihue por el sur), se quedaron con poco más de 500.000 . Con un promedio de 6.8 hectáreas por persona, la dotación en tierra de los indígenas se encontraba muy por debajo del promedio otorgado a los nuevos colonos nacionales y extranjeros (50 y 500 hectáreas respectivamente) ${ }^{58}$. El patrimonio colectivo indígena había sido severamente mermado. Los ricos agropastores y comerciantes del periodo colonial y republicano temprano habían sido transformados en campesinos pobres ${ }^{59}$. Finalmente, al entregar el título de merced al lonko de una «comunidad», la ley de radicación y sus funcionarios coloniales, ignorando la existencia de la posesión individual (i.e. condicionada por la pertenencia al grupo) que reglamentaba el acceso a la tierra al interior de las unidades sociales indígenas, inventaron el mito de la propiedad colectiva ubicada bajo la autoridad de un jefe ${ }^{60}$. Los antiguos distritos sociopolíticos desaparecieron

56 AYLWIN [45], p. 36.

57 ORMEÑo \& OSSES [20], p. 19. Según otros autores el número de personas radicadas fue de 82.629 en una superficie de 510.386,67 hectáreas (José AYLWIN \& Martín CORREA, «Tierras indígenas de Malleco: antecedentes histórico-legislativos y estudio de comunidades», en Tierra, territorio y desarrollo indígena. Temuco, Instituto de Estudios Indígenas, 1995, p. 58). La población censada como indígena en 1907 era de 101.118 personas.

58 José, MARIMAN, Pueblo mapuche. Estado y autonomía regional. Temuco, Centro de Estudios y Documentación Liwen, 1990, p. 14. Para más detalles sobre los mecanismos concretos de la radicación véase el estudio ya citado de AYLwIN [45].

59 Hay que señalar que contemporáneamente al proceso de «pacificación de la Araucania» chileno, los ejércitos argentinos habían llevado a cabo la llamada «conquista del desierto», poniendo fin a las redes comerciales transcordilleranas indígenas y acabando con la existencia del área pan-mapuche. Para un acercamiento a lo que aconteció allende la cordillera véase : Isabel HERNANDEZ (Coord.), La identidad enmascarada. Los Mapuche de los Toldos. Buenos Aires, EUDEBA, 1993.

60 «[...] la propiedad común de la tierra por el grupo de la reducción fue desde un comienzo una especie de ficción legal; de hecho, todas las tierras estaban divididas en parcelas que pertenecían a las familias componentes. Además los grupos domésticos debían quedarse en esas parcelas a partir de entonces, perdiendo la posibilidad de cambiarlas o extenderlas mediante la ocupación de las tierras comunes no cultivadas, puesto que éstas habían desaparecido [...]. Por otra parte, el grupo reduccional no podía dividirse en dos mediante el traslado de parte de éste a otro territorio sobre el cual nadie tuviera derechos, puesto que todas las tierras no asignadas a grupos reduccionales fueron declaradas propiedad estatal y vendidas a colonos chilenos» (Milan STUCHLIK, La vida 
y la nueva división territorial vino a sobreponerse a la estructura socioterritorial imperante en los siglos anteriores ${ }^{61}$. La desorganización de las estructuras étnicopolíticas macroregionales desembocó en la formación de una estructura aislada de comunidad reduccional ${ }^{62}$. Todo conflicto en materia de tierra debía desde ahora resolverse ante el Protector de indígenas, es decir afuera de los mecanismos internos a través de los cuales se dirimían tradicionalmente los conflictos. En fin, al transformarse en minoría étnica, el pueblo mapuche empezó a ser sometido al sistema de dominación global y se ubicó en una situación de dependencia respecto del Estado-Nación y de la sociedad dominante.

Centro de la política indígena (y no indigenista) del Estado, la radicación fue pensada como una medida de espera. Ahora bien, aunque concebidas como mouroirs culturales, las reducciones resultaron ser un lugar de reestructuración y de resistencia cultural frente al modelo dominante ${ }^{63}$. Podemos entrever ahí un efecto perverso (i.e. no querido o no esperado) de la política de hecho segregacionista del Estado chileno. Al despreocuparse de la situación económica, social y cultural indígena, al aislar y concentrar la población mapuche en reservas, las autoridades crearon las condiciones para que esta cultura se reprodujera y que la identidad autóctona perviviera. Así es como en ausencia de una política indigenista asimilacionista o integracionista coherente, la especificidad mapuche se mantuvo. Pero la perpetuación de esta especificidad en una situación de subordinación tuvo un precio: la marginación social y el empobrecimiento. Derrotados y subordinados, los Mapuches tendieron a desaparecer del escenario social nacional. Es durante este momento histórico que los indígenas perdieron visibilidad. El hecho de que Chile hubiera entrado en un proceso de «imaginarización de la nación como blanca, europea o criolla» 64 y que el Estado se hubiera construido sobre unas bases centralistas determinó en gran parte el proceso de relegación del Mapuche en los márgenes de la sociedad y de la historia nacional. De hecho, a pesar de las

en mediería. Mecanismos de reclutamiento social de los mapuches. Santiago, Soles ediciones, 1999, p. 227 -1era edición inglesa 1976-).

61 Tal como lo habían hecho los antiguos conquistadores con el otorgamiento a ciegas de títulos de encomienda, los nuevos funcionarios no consideraron la organización sociopolítica indígena en lov y rehue. La radicación tendió por otra parte a congelar y fijar las unidades sociales en un lugar determinado así como a reducir el territorio económico potencial de los grupos agro-pastores quienes en razón de la naturaleza misma de su economía no ocupaban el mismo lugar en forma continuada.

62 Sobre la organización sociopolítica indígena ante-pacificación, véase: BENGOA [33], BOCCARA [4] y MARIMAN [57], pp. 12-13.

${ }^{63}$ Sobre este tema véase el estudio de Louis C. FARON, Los Mapuche, su estructura social. México, Instituto Indigenista Interamericano, 1968 (1era edición inglesa USA, 1961). Para una interpretación distinta de la dinámica social mapuche (modelo transaccional) véase el estudio de STUCHLIK [60].

${ }^{64}$ Maxim Repetto, Políticas indigenistas en el Cono Sur. Argentina y Chile frente a los Mapuche, siglos XIX y XX. Universidade de Brasília, Instituto de Ciências Sociais, Dissertação de Mestrado, 1997, pp. 64-67. 
considerables diferencias existentes en las propuestas de las distintas organizaciones indígenas que se constituyeron en las primeras décadas del siglo XX, es dable notar que todas insisten en la situación de postergación social, económica y cultural en que se encuentra su pueblo ${ }^{65}$.

Como en otros territorios indígenas sometidos a un proceso de conquista y colonización interna, el sistema de reservas aparece aquí en toda su ambigüedad. Espacio de espera y postergación ajeno a la dinámica de crecimiento y de urbanización que lo rodea, sometida a un sistema de opresión y extorsión combinada, la reducción aparece también como un lugar a partir del cual los colonizados inten$\tan$ «enderezar un destino torcido» ${ }^{66}$ y resistir culturalmente ${ }^{67}$. Pero en los años 30 , la política para con los indígenas iba a conocer un nuevo vuelco. La división de las comunidades y la asimilación sociocultural del Mapuche se impusieron como los dos pilares de la «solución definitiva» al problema indígena. El desarrollo económico, la inculcación del arbitrario cultural occidental a través de la educación y de la salud y la igualdad de derechos (aunque sea formal) debían producir un efecto homogeneizador sobre «los componentes más atrasados de la sociedad nacional».

\section{DIVISION DE LAS COMUNIDADES, POLITICA ASIMILACIONISTA Y ORGANI- ZACIONES ARAUCANAS (1927-1970)}

Si bien, a partir de fines de los ãnos 20 , la política indígena impulsada desde el Estado tuvo un cariz claramente asimilacionista, hace falta tener en cuenta el papel jugado por las organizaciones indígenas y sus dirigentes durante este nuevo periodo. En efecto, éstos se transformaron en verdaderos actores sociales y políticos e intentaron influir en la definición de las nuevas normativas dictadas en relación a la división de las comunidades y a la recuperación de las tierras usurpadas. A pesar de las opiniones encontradas a propósito del tema de la división de las comunidades, tanto líderes indígenas como comuneros compartían la idea de que el sistema de reducción imperante resultaba totalmente insatisfactorio. $\mathrm{La}$

\footnotetext{
65 Sobre este tema véase el estudio muy bien documentado de Rolf FOERSTER \& Sonia MonteCino, Organizaciones, líderes y contiendas mapuches (1900 - 1970). Santiago, Ediciones Centro de Estudios de la Mujer, 1988.

66 Junta de caciques del Butahuillimapu, Osorno, 8/09/1997, citado por Rolf FOERSTER, «Una aproximación a la identidad huilliche desde sus narro-memorias», ponencia presentada al Ciclo de Conferencias, Mestizaje, nuevas identidades y plurietnicidad en América. Temuco, Instituto de Estudios Indígenas, 1999, p. 15 (actas por publicar).

67 Citando a José BENGOA [33], AYLwIN escribe: «A pesar de las limitaciones [...] la comunidad se transforma en un refugio para el mapuche, en un espacio que le permite dar continuidad a su historia y cultura, una cultura de resistencia que tiene por objeto impedir la aniquilación total» (José AYLWIN, «Antecedentes histórico-legislativos para el estudio de comunidades reduccionales mapuche», en Pentukun, n 4, Temuco, Instituto de Estudios Indígenas, 1995., p. 28).
} 
escasez de tierra, el aislamiento, la marginación y la ruptura con las jerarquías tradicionales constituían los mayores obstáculos al adelantamiento de la entonces llamada «raza araucana».

Ahora bien, cada organización tenía su propia concepción sobre el camino a seguir para salir de la pobreza y del estancamiento.

La Sociedad Caupolicán (fundada en 1910) insistía en la necesidad de educarse (trocar las armas por la instrucción, el fusil por el arado) y fomentar los nexos con el mundo político indigenista wingka. Su principal figura, Manuel Manquilef, definió desde el inicio el campo de lucha de la agrupación que dirigía desde 1916: «exigir la radicación de los mapuches no radicados, el no pago de contribuciones, la subdivisión de las comunidades, educación, denuncia y amparo constantes de los atropellos sufridos por los indígenas» ${ }^{68}$. Empero, en 1926, la Sociedad Caupolicán, encabezada por su nuevo presidente Arturo Huenchullán, se opuso a la ley de división (1927), cuyo principal artífice había sido el profesor Manquilef, ex-presidente de la agrupación y desde 1925 diputado del Partido Liberal. El argumento avanzado por los dirigentes de la Sociedad era que al dividir las comunidades y al terminar con las normativas cautelares se instauraría una igualdad de derecho que superpuesta a la desigualdad socioeconómica autóctona con los no-mapuches iba a acentuar el proceso de usurpación y pauperización. A partir del año 1931, la Sociedad Caupolicán, encabezada por el joven empleado de la Ford, Venancio Coñuepán, iba a tomar otro rumbo. Según el presidente de la nueva Corporación Araucana (1938) ya no se trataba de esperar ayudas o iniciativas exteriores. Es a través del desarrollo económico, de la ocupación de espacios dentro de las instituciones estatales y desde la antigua tradición de los caciques gobernadores que se trataba de luchar para la igualdad de derechos y el progreso del pueblo Mapuche. Como veremos más adelante, esta estrategia indigenista, populista e integracionista desarrollada por Coñuepán condujo la Corporación Araucana a formar una suerte de partido mapuche con dirigentes ubicados en lugares claves de la institucionalidad chilena. Frente a la amenaza que representaba el avance político indígena, los poderes económicos regionales y el Partido Agrario Laborista promovieron el dictado de una nueva ley (1961) cuyo objeto era acelerar el proceso de división y acabar con la existencia de «un grupo étnico separado del resto de la Nación chilena».

La otra organización que jugó un papel importante en la definición de una propuesta indígena original fue la Federación Araucana. Nacida en 1916, «hablaba desde el lugar de la identidad ancestral» ${ }^{69}$ adaptándose al nuevo campo de lucha wingka. Fue la primera en enfrentar directamente los poderes de Estado y económicos. Propuso la creación de una Republica Indígena y definió un proyecto de autonomía. Su líder, Manuel Aburto Panguilef, aliado de los partidos

68 FOERSTER \& MONTECINO [65], pp. 22-23.

69 Foerster \& MONTECINO [65], p. 152. 
izquierdistas, tenía un discurso con acentos milenaristas en que se mezclaban reivindicaciones de justica social para mapuches y obreros con aspiraciones nativas que le habían sido reveladas en sueños ${ }^{70}$. Precursora de una propuesta sincrética y autonomista, la Federeción Araucana fue demonizada y tildada de procomunista por los sectores ligados a la Iglesia y al poder latifundista regional.

Finalmente, la Unión Araucana, gestada en 1926 bajo la tutela de los Capuchinos, proponía la «occidentalización de la cultura mapuche y la entrada del indígena a la modernidad» ${ }^{71}$. El lema de la organización durante la Asamblea de 1936 fue «Religión, Patria, Familia, Cultura y Trabajo» ${ }^{72}$. Es a través de la evangelización, de la educación y de la asimilación que la miseria y las injusticias de que era víctima esta «raza dotada de cualidades físicas y morales innegables» iban a ser superadas. Sacar los indígenas «a la luz y al uso de la Iglesia y de la Nación», tal era el objetivo ${ }^{73}$.

De las tres organizaciones indígenas mencionadas, la que iba a jugar un papel descatado dentro del nuevo escenario fue la Sociedad Caupolicán, y en particular dos de sus máximos dirigentes: Manquilef y Coñuepán. El primero participó como diputado en la elaboración de la ley de 4 de agosto de 1927. Esta normativa tuvo una importancia radical puesto que «contenía las nuevas orientaciones que marcarían la política indígena de este período» ${ }^{74}$. En su artículo primero estipulaba la creación de un Tribunal Especial que tenía dentro de sus atribuciones proceder a la división de las comunidades indígenas con título de merced y la restitución integral de las tierras adjudicadas durante el período de la radicación. En 1930 se dictó una nueva ley que, como la anterior, tenía como meta concluir con el sistema de las comunidades mediante la aceleración de las divisiones y su posterior incorporación al sistema legal común. Bajo la presión de los terratenientes el Tribunal Especial fue sustituido por cinco juzgados de indios ${ }^{75}$. Finalmente, el decreto ley de 20 de mayo 1931 puso fin a la división obligatoria de las comunidades al exigir que por lo menos la tercera parte de los comuneros la pidiera. Como lo señala Valenzuela, «si bien la ley no consagró la indivisibilidad absoluta de la propiedad indígena, por lo menos, permitió la paralización de las divisiones ${ }^{76}$. Con todo, la participación indígena fue mínima y el proceso de división había comenzado. Y a pesar de que la integración de los autóctonos al

\footnotetext{
70 «Manuel Aburto Panquilef jamás abandonó la utopía que recogió de la izquierda: la República Indígena. En sus últimos años esta idea se le imponía por un mandato divino de los dioses, antepasados y ángeles. El lonko atendiendo al llamado de las divinidades se hizo machi [chamán]» (FOERSTER \& MONTECINO [65], p. 150).

${ }^{71}$ FOERSTER \& MONTECINO [65], p. 155.

72 FOERSTER \& MONTECINO [65], p. 153.

73 Citado por FOERSTER \& MONTECINO [65], p. 53.

74 VALENZUELA [53], p. 67.

${ }^{75}$ Los terratenientes declararon haber sido gravados en sus intereses por la ley 4.169 de 1927 en la medida en que habían tenido que devolver grandes extensiones de las tierras usurpadas.

76 VALENZUELA [53], p. 77.
} 
derecho común se realizase considerando su «grado de civilización o instrucción ${ }^{77}$, el sistema de transferencia de la propiedad indígena (capacidad de celebrar contratos, gravar o enajenar las hijuelas adjudicadas durante el proceso de división) ya tenía vigencia legal.

$\mathrm{Si}$ exceptuamos el periodo durante el cual los mapuches obtuvieron, con la nominación de Coñuepán como Ministro de Tierras y Colonización del General Ibañez (1952) y la creación de la DASIN ${ }^{78}$, su primer reconocimiento por parte del Estado, constatamos que los años que corren desde la primera ley de división (1927) hasta la ley indígena de 1972 se caracterizaron por un empeoramiento de la situación política, económica, social y cultural de los autóctonos.

A nivel organizativo, la derrota del movimiento indigenista generado por la Corporación Araucana de Coñuepán y la diseminación de las agrupaciones en todo el espectro político wingka a partir de 1960 significó la imposibilidad de llegar a una necesaria unidad étnica. A nivel de tierras, el total de comunidades divididas entre 1931 y 1971 fue de 832. Dadas las frágiles protecciones otorgadas por las distintas leyes, se calcula que alrededor de 100.000 hectáreas de las antiguas comunidades pasaron a manos de particulares no-indígenas ${ }^{79}$.

El debilitamiento económico se expresó también a través del proceso de minifundización progresiva (pérdida territorial y/o crecimiento demográfico) acompañado del proceso de transferencia de excedentes internos mediante las relaciones desiguales con los mercados locales ${ }^{80}$.

Correlativo a este desmejoramiento neto de las condiciones económicas, se generó un proceso de proletarización. La captación de una parte del valor del producto por el mercado y la minifundización condujeron a muchos jóvenes a migrar hacia las ciudades para incorporarse a los estratos más bajos del proletariado urbano. Pero como bien sabemos «cuando un indígena ha vendido su tierra y gastado su plata, no deja de ser indígena, se vuelve simplemente un indígena sin tierra» ${ }^{81}$. De suerte que concomitante al proceso de pauperización, los Mapuches de áreas rurales y urbanas fueron sometidos a una subordinación social y cultural sin precedente. Estigmatizados como «indios», insertados en una socie-

77 VALENZUELA [53], pp. 87-93.

78 Creada en 1953, la Dirección de Asuntos Indígenas tenía a su cargo la aplicación de la ley indígena. A pesar de ser controlada durante un tiempo por la Corporación Araucana y de intervenir a favor de los indígenas en los distintos Juzgados de Indios (lo que motivó la intervención de los terratenientes interesados en adquirir las tierras indígenas, la realización de un informe por parte del fiscal de la Corte de Apelaciones de Temuco en 1955 y la posterior victoria del poder económico regional a través de la dictación de la nueva ley 14. 511 de 1961) la Dirección tuvo pocos medios económicos para actuar y nunca tomó en cuenta el pluralismo en sus escasas medidas de orden educacional.

79 ORMEÑO \& OSSES [20], p. 21.

${ }^{80}$ Sobre este tema véase los estudios detallados de Wilson CANTONI [35] y Alejandro SAAVEDRA, La cuestión mapuche. Santiago, ICIRA (Instituto de Capacitaciones e Investigaciones en Reforma Agraria), 1971.

81 Rouland et al [18], p. 375. 
dad que justificaba la estratificación interétnica en base a un conjunto de estereotipos y prejuicios, los Mapuches fueron objetos de una política deliberadamente etnocéntrica y asimilacionista. La intervención de la sociedad dominante a nivel educacional se hizo sentir a partir de la ley de instrucción primaria de 1926 y se reforzó a través de las disposiciones contenidas en la ley de 1961 sobre creación de centros educacionales en las reservas. Las escuelas se multiplicaron en las zonas rurales imponiendo el arbitrario cultural occidental, acentuando la dinámica de aculturación impuesta pero sin entregar reales oportunidades de inserción en la sociedad dominante ${ }^{82}$. La distribución desigual de los recursos culturales (capital cultural) y de las oportunidades (capital social y económico) tendió a intensificar la dinámica aculturativa de inserción social subordinada. Instrumento de control cultural por excelencia, la educación monocultural monolingüe fue acompañada por la imposición de programas en salud que no tomaban en cuenta las concepciones autóctonas del cuerpo y de la enfermedad ${ }^{83}$.

El proyecto homogeneizador, progresivamente y gracias a la pauperización de los indígenas, iba a intervenir en todos los sectores de la realidad social autóctona. La violencia simbólica ejercida por los dispositivos ideológicos de estado hizo que para muchos la lucha contra la discriminación se identificara con el esfuerzo por la asimilación de la cultura nacional y con la lucha por la ascención social individual en la estratificación de clase ${ }^{84}$. Tal como lo escribe Cantoni, al final de este periodo, «la cultura mapuche se preservó como cultura de enclave reforzada por elementos característicos de una cultura de resistencia» ${ }^{85}$.

\footnotetext{
82 Pablo MARIMAN, «Demanda por educación en el movimiento mapuche en Chile, 1910 1995», en Pueblos indígenas, educación y desarrollo. Santiago, Centro de Estudio Para el Desarrollo de la Mujer/Instituto de Estudios Indígenas, 1997, pp. 129-201.

${ }^{83}$ En 1952 se conforma el Servicio Nacional de Salud. Si exceptuamos la tesis de Roger Yvon Kellner ([7]) que abarca esencialmente el periodo dictatorial (1973-1990), hay que reconocer que poco se ha analizado, desde el interior, el impacto de las políticas estatales sobre la sociedad mapuche y la naturaleza de las relaciones entre el Estado y esa minoría étnica.

${ }^{84}$ CANTONI [35], p. 320.

85 CANTONI [35], p. 327. Si bien el artículo de Cantoni constituye uno de los pocos estudios socioeconómicos detallados sobre el tema de la inserción mapuche en la sociedad nacional chilena, el marco teórico marxista usado por el autor no logra captar la especificidad de la dinámica cultural autóctona. Al caracterizar de parcial a la conciencia étnica mapuche y al interpretar las opciones políticas y percepciones indígenas en términos de «falsa conciencia» o de «desconocimiento de la realidad objetiva de clase subordinada», Cantoni no logra explicar la lógica social, cultural y política de este pueblo. He aquí lo que escriben con mucho acierto Foerster y Montecino a propósito de la interpretación que daban algunos teóricos marxistas de las tomas de terrenos realizadas por los comuneros mapuche en los años 60: «Sería engañoso traducir estas acciones a una perspectiva de clase y además revolucionaria. Una investigación de 1971 en las comunidades que habían recuperado sus tierras evidenció su «baja conciencia de clase» debido al espíritu «pequeño burgués» de los campesinos mapuchès (Berdichewsky). En otras palabras -y más adecuadas a la realidad indígena-, esas movilizaciones se enmarcaron en la tradición ya centenaria, de recuperación de sus espacios comunitarios (que le permitían, como grupo étnico, delimitar sus ámbitos económicos, políticos y sociales)» ([65], p. 287). Para un análisis del desfase entre aspiraciones indígenas y
} 
En fin, puede decirse que durante este periodo «la legislación indígena ha sido esencialmente antiindígena» ${ }^{86}$ y que la política indígena ha sido marcadamente asimilacionista.

\section{RECONOCIMIENTO DE LAS CULTURAS INDIGENAS Y POLITICA DE INTEGRACION: CONVERSACION INTERRUMPIDA CON EL PUEBLO... MAPUCHE (1970-1973)}

La nueva dinámica social, económica, política y cultural en que entró Chile a partir de los años 60 y que desembocó en la formación del gobierno de la Unidad Popular tuvo implicancias sobre la política indígena estatal. En primer lugar, el proceso de Reforma Agraria iniciado bajo el gobierno de Alessandri (ley de 1962) y que tomara un cariz más radical bajo el gobierno socialista de Salvador Allende no podía dejar de afectar a una población mapuche en su mayor parte rural ${ }^{87}$. En segundo lugar, el reconocimiento de la especificidad cultural indígena por parte del Ejecutivo planteaba por primera vez los problemas de la participación efectiva de los pueblos autóctonos en el desarrollo regional y nacional así como de su inserción en la sociedad desde una óptica cultural pluralista.

Ahora bien, las políticas aplicadas por el Estado con respecto a los indígenas en general y a los mapuches en particular no escapó del todo al escollo etnocéntrico. Para algunos intelectuales de la época, la estratifiación interétnica representaba la forma colonial de la estratificación de clase y la subcultura mapuche determinaba una identidad étnica que dificultaba la emergencia de una clara conciencia de clase entre los indígenas. Según otros, y desde una óptica voluntarista que poco tenía que ver con la lógica socioeconómica autóctona, la comunidad indígena debía recuperar los rasgos colectivistas que la habría caracterizado antes de que las múltiples leyes de división y la lógica de mercado hubieran empujado a los comuneros hacia la situación de pequeños propietarios individuales. Pero a pesar de esas limitaciones, la política indígena implementada por la UP se diferenció por lo menos en cuatro aspectos de la perspectiva asimilacionista adoptada desde que fuera dictada la primera ley de división de 1927: reconocer la existencia en el territorio nacional de grupos culturalmente diferenciados, hacer del asunto indígena un problema nacional, reconocer la deuda histórica que tenía el Estado para con los indígenas y sacar a la luz el tema de la participación autóctona.

proyecto revolucionario véase Ingrid SEGUEL-BOCCARA, Les passions politiques au Chili durant l'Unité Populaire (1970 - 1973). Paris, Éditions L'Harmattan, 1997, pp. 239-252 y pp. 267-271. Un reciente y novedoso estudio intenta acercarse a la manera como los indígenas interpretaron y vivieron las violaciones a los derechos humanos bajo el régimen del General Pinochet (Teresa DURAN, et al., Muerte y desaparición forzada en la Araucanía. Una aproximación étnica. Temuco, Ediciones Universidad Católica de Temuco, 1998).

86 ORMEÑO \& OSSES [20], p. 25.

${ }^{87}$ Sobre la Reforma Agraria véase Ingrid SEguEL-BocCARA [85].

R. I., 1999, n. ${ }^{\circ} 217$ 
$\mathrm{Al}$ reconocer oficialmente, en su proyecto de ley, que los indígenas habían sido despojados, marginados y discriminados durante décadas, el Ejecutivo abrió el camino hacia la legitimación de las antiguas reivindicaciones indígenas relativas a la escasez de tierras. Recogiendo las ideas planteadas por las propias organizaciones indígenas durante el primer y segundo Congreso Nacional Mapuche (1969 y 1970), las autoridades enviaron al Congreso un proyecto de ley que, después de numerosas enmiendas y apasionadas discusiones, fue aprobado en 1972.

¿Cuáles fueron los aspectos claves de esta nueva ley indígena y de qué modo éstos se insertaban en el programa más general de reformas sociales y económicas puesto en marcha por la UP?.

En primer lugar, la ley reconoció la pluralidad cultural existente en Chile ${ }^{88}$. Si bien no integró la autoidentificación como factor que permitiera determinar la calidad de una persona como indígena, logró desvincular la definición de la identidad indígena de la pertenencia a zonas rurales ${ }^{89}$. Tanto en la preparación de la ley como en los programas posteriores, las autoridades contaron con la colaboración de cientistas sociales (antropólogos, sociólogos, economistas), lo que demuestra que por primera vez se enfocaba el problema indígena como un asunto social y también cultural ${ }^{90}$. Después de haber sido silenciado durante décadas el tema indígena volvía a tener visibilidad en la sociedad chilena ${ }^{91}$.

88 «Por primera vez, una ley indígena delimitó desde el punto de vista étnico los sujetos del ordenamiento jurídico: «los indígenas»» (VALENZUELA [53], p. 138).

89 «Se tendrá por indígena [...] a la persona que se encuentre en alguno de los casos siguientes [...] 3- Que, habitando en cualquier lugar del territorio nacional, forme parte de un grupo que se exprese habitualmente en un idioma aborigen y se distinga de la generalidad de los habitantes de la República por conservar sistemas de vida, normas de convivencia, costumbres, formas de trabajo o religión, provenientes de los grupos étnicos autóctonos del país» («Ley 17.729 legisla sobre protección de los indígenas, en relación con el dominio, uso, goce, disposición y transferencia de sus tierras, y sobre desarrollo cultural, educacional y económico de dichos connacionales; crea el Insituto de Desarrollo Indígena», Diario Oficial, $\mathrm{n}^{\circ} 28.362,26-09-1972$, artículo $1^{\circ}$ ).

${ }^{90}$ Alejandro LIPSCHUTZ fue encargado por el Ejecutivo de realizar un estudio que permitiera establecer los criterios de definición de la calidad de indígena.

91 Actores de este proceso, Osses y Ormeño escriben en 1972: «El proyecto de ley que ha propuesto el Ejecutivo ha debido partir de varios hechos [...]. El «problema indígena» es un problema nacional [...]. Los indígenas se encuentran agraviados y descontentos, por lo que la sociedad chilena tiene que pensar seriamente en reconciliarse con ellos [...]. Los indígenas son distintos al resto de la población nacional. Lo importante es que culturalmente son diferentes. Erradamente algunos, intencionadamente otros, sostienen que los mapuches son iguales a todos los chilenos y que, en concecuencia, no deben establecerse en su beneficio normas jurídicas ni tratamientos distintos. Las autoridades del Gobierno Popular sostienen, por el contrario, que esta idea estereotipada ha servido como cortina de humo para ocultar todo el proceso de despojo y marginación a que se ha sometido durante muchos años a los pueblos indígenas. Lo honesto es reconocer una realidad objetiva: los grupos indígenas, especialmente los mapuches, constituyen una cultura que tiene claros y definitivos rasgos diferenciantes de la sociedad global» (OSSES \& ORMEÑo [20], pp. 25-26). El interés de esta cita es que demuestra que en la época no era un hecho tan evidente que los Mapuches fueran portadores de un cultura distinta a la cultura dominante. Tal como lo escribía Cantoni

R. I., $1999, \mathrm{n}^{\circ} 217$ 
Otro objetivo de la ley 17.729 era poner término al proceso de división e impulsar la recuperación de tierras a través de la restitución de las tierras usurpadas y la expropiación. El total de tierras restituidas a los mapuches durante este breve periodo fue de 68.381 hectáreas.

El tercer objetivo era promover el desarrollo económico y social indígena. Eso se lograría a través de la transformación del sistema de tenencia y explotación individual de la tierra por fórmulas cooperativas y comunitarias. El desarrollo debía ser integral (económico, social y cultural) por lo que el Instituto de Desarrollo Indígena ${ }^{92}$ estuvo encargado de llevar a cabo una política que respetara «la idiosincracia y las costumbres de los indígenas». Al prever la incorporación de indígenas al Consejo de Dirección Superior del IDI se buscó la participación activa de los autóctonos en la promoción del progreso e integración sin asimilación. El IDI tenía facultades para conceder créditos agrícolas y asistencia técnica, capacitar a los indígenas ${ }^{93}$, promover e integrar a las culturas autóctonas, elaborar programas de alfabetización, promocionar el desarrollo de la artesanía y fomentar el ingreso de indígenas en las universidades ${ }^{94}$.

Por primera vez en su historia el Estado chileno implementaba una política propiamente indigenista. Obviamente, el gobierno de Allende «encausó la cuestión mapuche dentro de los marcos de su propia lucha ideológica» ${ }^{95}$. Indudablemente, quedaba por definir el contenido concreto de la noción de «integración en el respeto de la idiosincrasia indígena». Evidentemente, las normas de desarrollo educacional contenidas en la ley no parecían tomar en cuenta la existencia de pautas de socialización propiamente autóctonas así como la existencia de un idioma propio que pudiera ser utilizado para implementar un programa de educación intercultural bilingüe. Pero a pesar de esas limitaciones que remiten al contexto sociohistórico e ideológico de la época, la política desarrollada por la UP marcó un precedente en la historia chilena respecto del tema indígena y sentó las bases de una construcción nacional pluralista. La instauración de un régimen dictatorial neoliberal iba a parar el proceso de reconocimiento de los derechos de

en la misma época a propósito de la discriminación imperante: «[...] dentro de un contexto nacional de evidente mezcla racial y de líneas de clase bien marcadas, los chilenos de clase media hacia arriba también se enorgullecen de una supuesta homogeneidad racial y de una pretendida pureza de raza, lo que denota la persistencia de prácticas racialmente discriminatorias [...]. El tema de la discriminación racial se volvió en Chile una «vexata questio». Como toda cuestión vergonzosa, está congelada por un pacto de silencio, se actúa como si no existiera y se espera de las personas bien educadas que no hablen de ella» (CANTONI [35], pp. 305-306).

92 El IDI vino a reemplazar la DASIN. Dependía del Ministerio de Agricultura y representaba una «persona jurídica de derecho público, organismo autónomo del Estado, con patrimonio propio y con plena capacidad para adquirir derechos y contraer obligaciones» (VALENZUELA [53], p. 166).

${ }^{93}$ En 1971 se creó el Instituto de Capacitación Indígena y se aumentó sustancialmente el número de becas para indígenas.

${ }^{94}$ Ley no 17.729 [89], títulos 2 y 3.

95 VALENZUELA [53], p. 173.

R. I., $1999, \mathrm{n}^{\circ} 217$ 
los pueblos autóctonos y postergar en dos décadas el debate insoslayable alrededor de los temas del etnodesarrollo, del pluralismo cultural y de la autonomía interna.

\section{TERMINATION POLICY A LA CHILENA: DEL HOMO INDIGENUS AL HOMO ECONOMICUS (1974-1989)}

Como minoría étnica dependiente de las dinámicas existentes en la sociedad mayor, los Mapuches fueron afectados por la revolución conservadora y autoritaria llevada a cabo bajo el régimen militar del general Pinochet ${ }^{96}$. Después de la paréntesis de la UP, se reanudó el proceso de división de las comunidades que empezara a fines de los años 20. Aplicando al problema indígena la política socio-económica general de inspiración neoliberal que tuviera como meta declarada hacer de Chile un país de pequeños propietarios individuales, las autoridades de la época dictaron dos decretos leyes (1979) cuyos ejes directores eran: 1) acelerar el proceso de división y liquidar las comunidades, 2) acabar con la existencia legal de los indígenas.

Concerniente al primer punto, el decreto-ley $\mathrm{n}^{\circ} 2.568$, considerando necesario terminar con las discriminaciones positivas contenidas en las normativas anteriores, estableció mecanismos que permitieran dividir las reservas a petición de un solo de sus miembros. Con el fin de agilizar los trámites de división, se preveía un procedimiento expedito y gratuito ante el juez de letras. Si bien se dictaba la imposibilidad de enajenar las hijuelas durante 20 años a partir de la fecha de inscripción en el Registro del Conservador de Bienes Raíces, la ley dejaba abierta la posibilidad de gravar o hipotecar las hijuelas a favor de cualquier organismo del Estado, de instituciones financieras crediticias o bancarias. Por otra parte, al no decir nada en relación con los arriendos, le nueva normativa «posibilitaba la firma de ese tipo de contratos hasta por 99 años» ${ }^{97}$.

En cuanto al segundo punto o paso de la política asimilacionista plasmada en la nueva normativa, ponía término al recurrente problema mapuche, al declarar la muerte legal del indígena: «A partir de la fecha de su inscripción en el Registro de Propiedad del Conservador de Bienes Raíces, las hijuelas resultantes de la

\footnotetext{
${ }^{96}$ Hace falta notar, aunque no tengamos el espacio de desarrollarlo aquí, que los indígenas no solamente dependen de las coyunturas políticas existentes en la sociedad mayor sino que llegaron a depender material, cultural y simbólicamente de la sociedad dominante. El proceso de aculturación de dependencia pasa por la aceptación del modelo dominante y la interiorización de pautas (estéticas, conductuales, discursivas, educacionales, etc.) que tienden a generar disposiciones duraderas (una suerte de habitus étnico), ubicando al Mapuche en una situación de dominado. Para un análisis de este proceso de dependencia véase KELLNER [7].

97 José AYLWIN \& Eduardo CASTILlO, Legislación sobre indígenas en Chile a través de la historia. Santiago, Comisión Chilena de Derechos Humanos, 1990, p. 13.
} 
división de las reservas dejarán de considerarse tierras indígenas, e indígenas a sus dueños o adjudicatorios ${ }^{98}$. La sustitución del Instituto de Desarrollo Indígena por el Instituto de Desarrollo Agropecuario (INDAP) es otra expresión del afán de acabar de una vez por toda con el problema indígena. La nueva legislación, elaborada sin participación alguna de los pueblos y organizaciones autóctonos, decretó la muerte del homo indigenus y el nacimiento de un hombre nuevo, «más libre y más racional», el homo economicus chilensis. En base a esos decretos leyes, se procedió, entre 1979 y 1990 , a la división de la casi totalidad de las reducciones. 72.068 títulos de dominio fueron entregados por una superficie total de aproximadamente 465.000 hectáreas ${ }^{99}$.

Tal como lo señaló a la sazón el antropólogo chileno José Bengoa, el dictado de la nueva normativa representó «el intento de supresión de un pueblo, de «solución definitiva» del problema indígena en Chile» ${ }^{100}$. No solamente porque se decretó el fin del indígena como grupo específico o minoría étnica, sino porque al poner término a las discriminaciones legales positivas (igualdad formal) se consagraron y ampliaron las discriminaciones sociales, económicas y culturales existentes (desigualdad real) ${ }^{101}$. De hecho, a ojos de las autoridades de la época la ley de división aparecía como la mejor palanca para terminar con el problema del minifundio y permitir el desarrollo económico regional ${ }^{102}$. La distribución desigual de las distintas especies de capital ${ }^{103}$ entre indígenas y no-indígenas y la pauperización producida por el proceso de captación de una parte del valor del producto interno por el mercado ${ }^{104}$, hacía que el horizonte más probable fuese la concentración de las tierras en las manos de los más provistos en capital económico, cultural, social y político. Por otra parte, la penetración de los mecanismos del libre mercado al interior de las reservas y el fin de la propiedad comunal cumulado con la distribución desigual de capital entre las mismas unidades familiares indígenas permitía conjeturar una acentuación de la diferenciación interna. En fin, se trataba, tanto a través de mecanismos impersonales (la lógica de mercado, la reasignación de recursos de «modo racional») como de medidas y mecanismos

98 «Decreto Ley N².568, de 1979», Diario Oficial, n 30.326, 28-03-1979, Capítulo I, artículo $1^{\circ}$, b.

99 Aylwin \& CASTILlo [97], p. 14. Sobre los mecanismos y efectos concretos de la división de las comundades véase: AYLWIN \& COOREA [57], pp. 64-66; José BENGOA, La división de las tierras mapuches. Santiago, Grupo de Investigaciones Agrarias, 1982, pp. 20-25; KelLNER [7], pp. 142-178; Elizabeth PARMELEE, «Decreto ley 2568, sus efectos e implicancias», en Revista Liwen, $\mathrm{n}^{\circ}$ 3. Temuco, Centro de Estudios y Documentación Mapuche, 1990, pp. 4-11.

100 BENGOA [99], p. ii.

101 BENGOA [99], p. 3.

102 En los años 40 se llegó a hablar de «cinturón suicida» para referirse a las propiedades mapuches que «impedían el progreso» en la zona (FOERSTER \& MONTECINO [65], pp. 277-281).

${ }^{103}$ En el sentido que le da el sociológo Pierre Bourdieu.

104 Sobre los mecanismos que hacen del mercado un sistema de expropiación permanente véaSe BENGOA [99], pp. 25-41 y SAAVEDRA [80].

\section{R. I., $1999, \mathrm{n}^{\circ} 217$}


sutiles de imposición de un orden legítimo (incentivo proporcionado a los mapuches «más capaces» o «menos rebeldes» ${ }^{105}$, aprovechamiento de la concepción que los indígenas se hacían del Estado y de sus agentes como proveedores de bienestar, de protección y de prestigio ${ }^{106}$ ) de solucionar el problema indígena por destrucción interna ${ }^{107}$. Como lo señala Roger Kellner, tanto la nueva legislación como la política estatal desarrollada durante los años dél régimen militar, se dirigieron exclusivamente hacia las unidades familiares en desmedro de la lógica social comunitaria ${ }^{108}$. De suerte que si la UP creó (por la vía democrática, a través de la discriminación positiva y la recuperación de las tierras usurpadas) el

${ }^{05}$ En 1980, el INDAP crea el programa de «subsidio rural». La obtención del subsidio (cuya principal medida consistía en la entrega de una casa prefabricada) estaba condicionada por la posesión de un título de dominio. En la práctica, los indígenas beneficiados por el subsidio fueron muy a menudo los que disponían de un volumen de capital social y político (relaciones con las autoridades locales, apoyo a Pinochet durante la campaña por el plebiscito de 1988, pertenencia a la iglesia evangélica) superior al de los otros comuneros.

${ }^{106} \mathrm{La}$ larga historia de conflictos entre Mapuche y Huinca asentados en la región, el proceso de pauperización y estancamiento económico de las comunidades, la penetración de los dispositivos ideológicos de Estado en los ámbitos sanitario, educacional, económico y jurídico así como las medidas de protección dictadas por las autoridades hicieron que la acción de Estado apareciera, para muchos indígenas, como legítima y deseable. Es a través de este proceso sociohistórico que se fue generando un habitus étnico que dicta que el orden establecido por la autoridad central y reafirmado por sus agentes es legítimo. La autonomía de las unidades familiares y la debilidad del leaderhship que caracterizan la organización social indígena (BOCCARA [4], KELLNER [7], STUCHLIK [60]) y que funcionaron como defensa «natural» durante la época colonial, fueron aprovechadas por el Estado chileno en el nuevo contexto post-reduccional. Como lo señala Kellner: «[...] the Chilean state has played a fundamental role in setting the conditions under which Mapuche society would operate in this century, and state institutions have been by far the most ubiquitous and powerful Huinca forces in Mapuche lives. [...] the national state has been the most prominent representative of Chilean society to the Mapuche, and interaction with its officials and its institutions has played the principal role in forming Mapuche belief in the "existence of e legitimate order». [...] the dispositions of a majority of reduccion Mapuche suggest habituated acceptance of the state's claim to legitimacy and superiority. As well as a dominator, it is also seen as a protector and benefactor» ([7], pp. 132-133). Foerster y Montecino afirman que «El Estado, desde muy antiguo, fue para los mapuches una instancia de mediación con los huinca y para sus propios problemas internos» ([65], p. 88).

107 BENGOA [99], p. 11.

108 Kellner ecribe: «[...] household interests, rather than comunity solidarity, are reinforced by the actions of the state and its officials» ([7], p. 152); y más lejos, a propósito de los mecanismos de dependencia que hacen que las políticas de estado hayan renforzado un rasgo de la organización social indígena (autonomía de la unidad familiar) y menoscabado los espacios de cooperación y solidaridad comunitaria: «Beside the potential material beniefits from associating with state officials, there are also social benefits to be realised. Social prestige is gained by associating with Huinca - the more important the Huinca, the higher the prestige. This reflects an invidious psychological dependence on Chilean society" ([7], p 153). Las políticas sanitaria, educacional y organizacional llevadas a cabo durante la dictadura tendieron también a fơmentar la independencia de las unidades familiares, a acelerar. el proceso aculturativo y a acentuar aún más la idea según la cual la reducción era un lugar sin futuro del cual había que migrar (KELLNER [7], pp. 179-218).

R. I., $1999, \mathrm{n}^{\circ} 217$ 
mito de la tenencia colectiva y de la economía comunal, la dictadura impuso (por la coacción, la manipulación y los mecanismos de la dominación simbólica) la ficción de un mapuche pequeño empresario ${ }^{109}$.

\section{LA LEY INDIGENA DE 1993: ¿UNA NUEVA ERA EN LAS RELACIONES ESTADO- PUEBLOS INDIGENAS?}

El peligro representado por los decretos leyes de 1979 así como la tentativa de incorporación de las comunidades a las estructuras dictatoriales locales a través de la creación de consejos comunales ${ }^{110}$ generó una reacción tanto por parte de los opositores al régimen militar como de algunos sectores del mundo indígena. Es así como a fines de los años 1970 y a principios de 1980 se crearon numerosas organizaciones mapuches ${ }^{111}$. Aunque su representatividad y arraigo en las comunidades fuesen bastante limitados ${ }^{112}$, los contactos establecidos entre esas organizaciones y el movimiento político de lucha por la recuperación de la democracia hizo que el tema de los derechos de los pueblos autóctonos se integrara a la plataforma de la Concertación de Partidos por la Democracia. En 1989, se suscribió un Acta de Compromiso entre el candidato de la Concertación Patricio Aylwin y las organizaciones indígenas. En 1990, el nuevo gobierno democrático creó la Comisión Especial de Pueblos Indígenas (CEPI) que tuviera como principal tarea la elaboración de un proyecto de ley indígena ${ }^{113}$. Tras largos y ásperos debates, el proyecto de ley indígena fue aprobado por el parlamento, no sin antes haber introducido en él considerables modificaciones. Dada la tradición centralizadora chilena y los intereses económicos en juego, no es de extrañarse que los principales reparos que los partidos de oposición derechista hicieron tuvieran

\footnotetext{
${ }^{109}$ Encontramos una prueba más del funcionamiento de un habitus étnico dominado que tiende a renforzar la dinámica de dominación impuesta desde el exterior en el hecho de que muchos mapuches aceptaron el proceso de división en parte porque al tener un título de dominio ganaban, no solamente en seguridad, sino también en estatus. Se ubicaban al mismo nivel que cualquier propietario wingka de la zona: «Gaining legal title was also seen by many Mapuche as tantamount to being accepted as the equals, if not in size at least in form, of other Chilean landholders. Thus, handing out titles was partially taken as handing out legitimacy; this played on the important sense of self-worth that many Mapuche strive for. The regime exploited this factor by promising access to programs (subsidios, access to credit) previously denied to those who did not have legal title to their land» (KELLNER [7], p. 171).

110 KELLNER [7], pp. 155-156.

111 Rolf FOERSTER, Condiciones de emergencia, ideologías y programas de las organizaciones mapuches. Santiago, Grupo de Investigaciones Agrarias, 1983.

112 KELLNER [7], pp. 240-247.

113 Diez representantes de los pueblos autóctonos chilenos fueron incorporados al Consejo de la CEPI (AYLWIN [1]).
}

R. I., 1999, n. ${ }^{\circ} 217$ 
relación con el uso del término «pueblos indígenas», considerando que representaba una amenaza en contra del carácter unitario del estado ${ }^{114}$.

Presentemos pues los principales aspectos de la ley $\mathrm{n}^{\circ} 19.253$ promulgada en 1993, y que rige hasta la fecha las relaciones entre el Estado chileno y las «etnias» indígenas.

En primer lugar, la nueva normativa reconoce la existencia de etnias indígenas en el territorio nacional. A semejanza de la ley de 1972, desvincula la definición del indígena de la radicación en tierras indígenas, integrando elementos culturales y de descendencia. Incorpora además como criterio de determinación de la calidad de indígena la autoidentificación. En segundo lugar, al dictar que «el Estado valora su existencia [de las etnias indígenas] por ser parte esencial de las raíces de la Nación Chilena, así como su integridad y desarrollo, de acuerdo a sus costumbres y valores» ${ }^{15}$, la ley reconoce el pluralismo cultural existente en Chile. En tercer lugar, se dictan mecanismos tendientes a proteger las tierras indígenas y se crea un Fondo de Tierras y Aguas con el fin de adquirir tierras para personas o comunidades. En cuarto lugar, se crea un Fondo de Desarrollo indígena dirigido a financiar programas especiales así como áreas de desarrollo entendidas como «espacios territoriales en que los organismos de la administración del Estado focalizarán su acción en beneficio del desarrollo armónico de los indígenas y sus comunidades». Finalmente, en el ámbito cultural y educacional la nueva ley entiende promover y proteger las culturas e idiomas indígenas así como desarrollar, en las áreas de alta densidad indígena, un sistema de educación intercultural bilingüe, para que los autóctonos puedan «desenvolverse en forma adecuada tanto en su sociedad de origen como en la sociedad global». Esta nueva política estará a cargo de la Corporación Nacional de Desarrollo Indígena, organismo «dotado de personalidad jurídica y patrimonio propio, sometido a la supervigilancia del Ministerio de Planificación y Cooperación». En el Consejo Nacional de este organismo se incorporarán ocho representantes indígenas.

En resumen, la ley indígena de 1993 destaca el carácter pluriétnico de la Nación Chilena y pone énfasis en la necesidad de promover el «desarrollo indígena con identidad». Indudablemente, esta nueva normativa representa un avance en el reconocimiento de los derechos de los autóctonos. Además, desde su promulgación, el Estado ha implementado novedosos programas interculturales en los ámbitos claves de la educación y de la salud ${ }^{116}$. De acuerdo al artículo 39 de la

\footnotetext{
114 AYLwin [1], p. 16.

115 Ley indígena [2], Párrafo $1^{\circ}$, artículo $1^{\circ}$.

116 Como lo ha demostrado Roger Kellner ([7], pp. 179-218), la salud y la educación fueron los pilares de la política asimilacionista del gobierno anterior y de manera general de todas las políticas indígenas llevadas a cabo desde principios de siglo. Para una visión bien documentada de la implementación de un programa de educación intercultural bilingüe y de la reforma educacional véase, Eliseo CAÑULEF, Introducción a la educación intercultural bilingüe en Chile. Temuco, Instituto de Estudios Indígenas, 1998. Sobre los desafíos que representa la revitalización de los
} 
ley, que estipula que la CONADI debe «velar por la preservación y la difusión del patrimonio arqueológico, histórico y cultural de las etnias», se ha iniciado una reflexión sobre la gestión del patrimonio indígena ${ }^{117}$ y se asignaron más recursos para la promoción de las culturas autóctonas. En 1998, el presidente en ejercicio Eduardo Frei declaró el día 24 de junio, Día Nacional de los Pueblos Indígenas ${ }^{118}$.

Así, después de más de un siglo de una política de corte deliberadamente asimilacionista, el Estado chileno ha puesto en marcha una política indígena que, según la tipología establecida en el informe Martínez Cobo, combina la fusión y el pluralismo ${ }^{119}$. Fusión ya que los programas interculturales pretenden, por lo menos teóricamente, producir una nueva cultura. Pluralismo, porque a través de la promoción y protección de los estilos de vida y territorios de las etnias nacionales se intenta preservar la especificidad cultural indígena y se reconoce la plurietnicidad de la Nación Chilena. Empero, a pesar de que la ley de 1993 constituye uno de los síntomas de la evolución que ha conocido la política indígena chilena en poco menos de una década, conviene reseñar las grandes limitaciones que padece.

En primer lugar, al nivel jurídico, observamos que al no reconocer la existencia de «pueblos indígenas», la ley se ubica en una posición bastante conservadora respecto de las normativas internacionales vigentes ${ }^{120}$. Por otra parte, al no tomar en cuenta la existencia de tratados anteriores firmados entre las «Naciones Indias» y la Corona Española tampoco integra los últimos aportes de la doctrina

idiomas indígenas véase, Francesco CHIODI \& Elisa LONCON, Crear nuevas palabras. Innovación y expansión de los recursos lexicales del Mapuzugun. Temuco, Instituto de Estudios Indígenas, 1999. A propósito de la implementación de programas en salud intercultural véase: Primer encuentro nacional salud y pueblos indígenas (Saavedra, 1996). Temuco, Servicio de Salud Araucanía, 1997; Salud, Cultura y Territorio: bases para una epidemiología intercultural. Taller nacional salud y pueblos indigenas. Temuco, Servicio de Salud Araucanía Sur, 1998.

117 Ximena NAVARro HaRris (Comp.), Patrimonio arqueológico indígena en Chile. Reflexiones y propuestas de gestión. Temuco, Instituto de Estudios Indígenas-UNESCO, 1998.

118 El día 23 de junio (fecha cercana al solsticio de invierno), los Mapuche celebran el Wetripantu (nueva salida del sol) que marca el inicio de un nuevo ciclo.

119 José R. MARTINEZ COBO, Étude sur le problème de la discrimination à l'encontre des populations autochtones, vol. V, 1986 (Citado por RoULAND, et al. [18], pp. 397-400).

120 Notemos que el hecho de hablar de «etnia» y no de «pueblo», no solamente remite a un problema jurídico. Tiene que ver también con las luchas de clasificación que se ubican en la base de la reproducción del orden legítimo y dominante. Así, calificar a los indígenas de «etnias» es hacerlos existir en tanto que «etnias», es decir como agrupaciones humanas pre-estatales, pre-modernas. Por lo tanto es reafirmar de manera sutil que su identidad es pre-nacional. Muchos dirigentes indígenas, que conocen el papel fundamental del lenguaje y la importancia de nombrar las cosas, llevan a cabo una lucha permanente en contra de la doxa (representaciones dominantes) con el fin de acabar con las categorías de percepción y oposiciones estereotipadas (educado/no-civilizado, biomedicina/brujería, rubio-bonito/moreno-feo, etc.) que hacen que el sistema de dominación pueda reproducirse sin violencia aparente e incluso con la complicidad de los mismos dominados. 
internacional en materia de teoría de los derechos autóctonos ${ }^{121}$. Finalmente, al no considerar el asunto del derecho consuetudinario, sigue enunciando que el derecho oficial, el del Estado Chileno, es el único orden jurídico existente. En segundo lugar observamos que el sistema de educación intercultural bilingüe tal como lo define la ley tiene un carácter unilateral, puesto que contempla que sólo los indígenas serán los beneficiarios de esos programas. En tercer lugar, el fenómeno indígena urbano no ha sido considerado en toda su magnitud. Ello representa una falta notable (de los 928.060 mapuches censados en 1992, más del $80 \%$ vive hoy en día en pueblos, ciudades y zonas densamente pobladas ${ }^{122}$ ) y revela, a pesar de la letra de la ley, una concepción esencialista y estrecha de la misma noción de identidad indígena.

En cuarto lugar, si la idea central de la nueva política indígena es la de desarrollo con identidad o etnodesarrollo, conviene señalar que no se ha definido con claridad el contenido de este nuevo concepto que remite las más de las veces a unas infra-ideologías o representaciones estereotipadas de la realidad indígena ${ }^{123}$. Respecto a ello los legisladores y agentes desarrollistas deberán tomar en consideración tanto los debates socio-antropológicos sobre las nociones de cultura, tradición, transformación e historicidad como las determinaciones de las necesidades que emanan de las propias sociedades autóctonas. Por otra parte, constatamos que la disociación entre desarrollo económico y derechos de los pueblos autóctonos tiende a desembocar en la expoliación territorial ${ }^{124}$. Desde este punto de vista, la nueva normativa choca contra el modelo económico neoliberal imperante y los intereses de las grandes empresas forestales. En quinto lugar, si bien la ley entiende penalizar las discriminaciones para con los indígenas, no se han impulsado programas de investigación a nivel nacional para reflexionar sobre los mecanismos del sistema de dominación, de la violencia simbólica y del racismo socioétnico que padecen los autóctonos.

Finalmente la política indígena actual se enfrenta a la reciente evolución del movimiento y de las demandas indígenas. La agudización de los conflictos de tierras y la multiplicación de las tomas o recuperaciones de terrenos durante los

121 Véase el estudio de Miguel Alfonso Martínez sobre los tratados entre Estados y pueblos autóctonos presentado en RoULAND, et al. [18], pp. 401-402.

122 XVI Censo Poblacional de Población 1992. Población Mapuche. Tabulaciones Especiales. Temuco, Instituto de Estudios Indígenas-Instituto Nacional de Estadísticas, 1998; Los Mapuches: comunidades y localidades en Chile. Santiago, Instituto Nacional de Estadísticas-SUR Ediciones, 1996; Marcos VALDES, «Notas sobre la población mapuche de la región metropolitana: un avance de investigación», en Pentukun, $n^{\circ}$ 5. Temuco, Instituto de Estudios Indígenas, 1996, pp. 41-66.

${ }^{123}$ Sobre este tema véase Jean-Pierre Olivier DE SARDAN, Anthropologie et développement. Essai en socio-anthropologie du changement social. Paris, Éditions Karthala, 1998, cap. 3.

${ }^{124} \mathrm{El}$ caso más famoso es el de la construcción por ENDESA de centrales hidroeléctricas en la cuenca del río Bío-Bío donde viven grupos Mapuche-Pewenche. Sobre este tema véase Roberto MORAlES, et al., Ralco. Modernidad o etnocidio en territorio mapuche. Temuco, Instituto de Estudios Indígenas, 1998.

R. I., $1999, \mathrm{n}^{\circ} 217$ 
años 1998 y 1999 han sido propicios a la aparición de Coordinadoras y agrupaciones comunales y regionales que contestan el papel de mediación de la CONADI y no reconocen la representatividad de las organizaciones indígenas incorporadas en las estructuras intermediarias. La transformación de la percepción que se tenía del problema indígena en un contexto de extrema pobreza y la lentitud con la cual se han llevado a cabo las compras de tierras por parte de la CONADI hacen que muchos comuneros ya no se contenten con la propuesta de un pluralismo abstracto. Las útimas demandas indígenas se formulan en términos de autonomía interna, de autodeterminación y de descolonización interna. Muchos mapuches ya no piden participación sino que exigen del Estado (respaldándose en los avances de las normativas internacionales) un nuevo trato que contemple la posibilidad de determinar ellos mismos cuáles serán los caminos a seguir en el futuro. El problema mapuche ya no es únicamente un problema de tierra (si es que lo fuese algún día), se ha transformado en un asunto de territorio ${ }^{125}$.

Before the indigenous law of 1993 recognized the existence of cultural pluralism in the national territory and set up the basis for the participation of «the Chilean ethnic groups», the aboriginal peoples were merely considered as legal «objects». Indeed, the indigenous policy implemented by the Chilean state since independence was mainly characterized by the state's will to assimilate the indigenous people. This article deals with the nature of the relations that the Chilean nation (imagined as homogeneous and european) and the state (centralized and looking for territorial unity).established with the Mapuche, one of the biggest indigenous groups in Latin America.

\footnotetext{
125 Para más informaciones sobre las legislación y .política indígenas en Chile véase los estudios siguientes: José AYLWIN, «Tierra mapuche: derecho consuetudinario y legislación chilena», en. Rodolfo Stavenhagen \& Diego ItURRALDe (Comp.), Entre la ley y la costumbre. El derécho consuetudinario indígena en América Latina. México, Instituto Indigenista Interamericano, 1990, pp. 333-354; José BENGOA, «Breve historia de la legislación indígena en Chile», en Anuario Indigenista, vol. XXIX. México, Instituto Indigenista Interamericano, 1990, pp. 17-57; Staffan BERGLUND, The national integration of Mapuche: ethnical minority in Chile. Stockolm, Almqvist \& Wiksell, 1977; Hector GoNZALEZ, «Propiedad comunitaria o individual. Las leyes indígenas y el pueblo mapuche», en Nütram, n⿳亠 2, año 3. Santiago, Centro Ecuménico Diego de Medellín, 1986, pp. 7-13; Alvaro JARA, Legislación indigenista en Chile. México, Instituto Indigenista Interamericano, 1956; Jorge VERGARA, et al., La propiedad huilliche en la provinca de Valdivia. Temuco, CONADI, 1996; Cristian VIVES, Legislación sobre indígenas en Chile: integración o asimilación. Santiago, Grupo de Investigaciones Agrarias, 1982.
}

\section{R. I., $1999, \mathrm{n}^{\circ} 217$}

